\title{
Outdoor Performance Assessment of New and Old Photovoltaic Panel Technologies Using a Designed Multi-Photovoltaic Panel Power Measurement System
}

\author{
Mehmet Karabulut $\mathbb{D}^{1}{ }^{1}$ Huseyin Kusetogullari $\mathbb{D},{ }^{2,3}$ and Sinan Kivrak $\mathbb{D}^{4}$ \\ ${ }^{1}$ Department of Electrical and Computer Engineering, Yildirim Beyazit University, Ankara, Turkey \\ ${ }^{2}$ Department of Computer Science, Blekinge Institute of Technology, 37141 Karlskrona, Sweden \\ ${ }^{3}$ School of Informatics, Skövde University, 54128 Skövde, Sweden \\ ${ }^{4}$ Department of Electrical and Electronic Engineering, Yildirim Beyazit University, Ankara, Turkey \\ Correspondence should be addressed to Huseyin Kusetogullari; huseyinkusetogullari@gmail.com
}

Received 16 June 2020; Revised 10 August 2020; Accepted 1 September 2020; Published 17 September 2020

Academic Editor: Jiangbo Yu

Copyright (c) 2020 Mehmet Karabulut et al. This is an open access article distributed under the Creative Commons Attribution License, which permits unrestricted use, distribution, and reproduction in any medium, provided the original work is properly cited.

\begin{abstract}
This paper presents a new multi-photovoltaic panel measurement and analysis system (PPMAS) developed for measurement of atmospheric parameters and generated power of photovoltaic (PV) panels. Designed system presented with an experimental study evaluates performance of four new and four 5-year-old PV panel technologies which are based on polycrystalline (Poly), monocrystalline (Mono), copper indium selenide (CIS), and cadmium telluride (CdTe) in real time, under same atmospheric conditions. The PPMAS system with the PV panels is installed in Yildirim Beyazit University, Ankara Province, in Turkey. The designed PPMAS consists of three different subsystems which are (1) photovoltaic panel measurement subsystem (PPMS), (2) meteorology measurement subsystem (MMS), and (3) data acquisition subsystem (DAS). PPMS is used to measure the power generation for PV panels. MMS involves different types of sensors, and it is designed to determine atmospheric conditions including wind speed, wind direction, outdoor temperature, humidity, ambient light, and panel temperatures. The measured values by PPMS and MMS are stored in a database using DAS subsystem. In order to improve the measurement accuracy, PPMS and MMS are calibrated. This study also focuses on outdoor testing performances of four new and four 5-year-old PV panels. Average monthly panel efficiencies are estimated as $8.46 \%, 8.11 \%, 5.65 \%$, and $3.88 \%$ for new Mono, new Poly, new CIS, and new CdTe PV panels, respectively. Moreover, average monthly panel efficiencies of old panels are calculated as $8.22 \%$, $7.85 \%, 5.35 \%$, and $3.63 \%$ in the same order. Test results obtained from the experimental system are also statistically examined and discussed to analyze the performance of PV panels in terms of monthly panel efficiencies.
\end{abstract}

\section{Introduction}

Increasing energy demand and decreasing fossil-based energy sources accelerate the trend towards renewable energy worldwide. As reported by the International Energy Agency (IEA), total renewable energy-based potential in the world is expected to grow by $50 \%$ that corresponds to approximately 1220 gigawatts of increase between 2019 and 2024 [1]. In addition, it is estimated that about $25 \%$ and $57 \%$ of the renewable energy will be generated using wind tribunes and solar panels, respectively [1]. Hence, the trend and popularity of the renew- able energy are growing rapidly. Note that this study focuses on analyzing various types of photovoltaic (PV) panel technologies which are connected to the proposed measurement system and examining power generation performance of these technologies under varying daily weather parameters.

$\mathrm{PV}$ energy is one of the most important renewable energy sources with widespread electricity generation in different places such as solar farm and rooftop [2]. With the growth of renewable energy generation, it is important to provide a trade-off between payback period of renewable energy investment and lifetime of PV panels. According to the PV panel 
technologies, the payback period of investment is variable because power generation performance of $\mathrm{PV}$ panels is affected by two main factors which are (1) panel efficiency and (2) varying weather conditions. By considering these two main factors, the PV panel characteristic parameters must be verified for effective power generation. In order to achieve the best characteristic parameters of PV panels, manufacturers work on developing the PV panels and evaluate the peak power of them, within the scope of standard test conditions (STC) that are defined with (1) $25^{\circ} \mathrm{C}$ PV cell temperature, (2) $1000 \mathrm{~W} / \mathrm{m}^{2}$ irradiance, and (3) 1.5 air mass (AM1.5) [3]. However, it is highly likely that generated power of manufactured PV panels in STC environment is different than outdoor environment. In other words, the actual power generation of the evaluated PV panels can be achieved in STC environment but it cannot be obtained under real case conditions [4]. This difference may cause power loss in energy generation, daily, weekly, monthly, and yearly, due to the varying meteorological conditions in different locations. In order to decrease the power loss and increase PV panel efficiency, different materials have been used to produce and develop different types of PV panels. For instance, conventional crystalline silicon PV cells have doped junctions such as "emitters" or "back surface fields" [4]. Amorphous silicon PV cells are mostly made by chemically vaporized a thin coat of silicone, placing on a surface such as plastic, metal, or glass [5]. Namely, cadmium telluride PV cells are formed by cadmium telluride and cadmium sulphide $\mathrm{p}-\mathrm{n}$ junction materials on a glass substrate [6]. Copper, gallium, indium, and selenide materials are deposited on a substrate layer by a sequence of chemical processes to form copper indium diselenide PV cells [7]. Polycrystalline, monocrystalline, thin film produced by CIS material, and thin film produced by CdTe material are widely used for renewable energy generation since these technologies provide several advantages in terms of price, energy efficiency, and lifetime $[8,9]$.

Silicon is a leading material used in the production of monocrystalline, polycrystalline, and thin film modules, which corresponds to more than $90 \%$ of the annual solar cell production [10]. In monocrystalline silicon cells, each solar cell is made from a single source of silicon. Besides this, monocrystalline silicon cells are produced by cutting $300 \mu \mathrm{m}$ thick cylindrical bars of monocrystalline silicon in special ovens [11]. On the other hand, polycrystalline silicon cells are made by combining melted pure silicone blocks [11]. Thin film cells are made from photovoltaic material placed between one or more thin layers, such as glass, plastic, or metal [12]. There are different types of thin film panels which are made by different materials such as CIS, CdTe, and amorphous Si photovoltaic materials. CIS-based thin film cells consist layers of $\mathrm{ZnO}, \mathrm{CdS}, \mathrm{CIS}$, and $\mathrm{Mo}$, which are organized on a glass, metal, or polymer substrate, whereas CdTe-based thin film modules are formed from transparent conductive oxide (TCO) layers such as $\mathrm{SnO} 2$ or $\mathrm{Cd} 2 \mathrm{SnO} 4$ [12]. The electricity generation performance of these PV panels may differ according to the locations. For instance, monocrystalline and polycrystalline PV panels have been installed to generate electricity in Bursa, Turkey [13]. The results are obtained with one week experiment, and they show that monocrystalline PV panel generates slightly more electricity than polycrystalline. In [14], monocrystalline $(2.35 \mathrm{~kW})$, polycrystalline $(2.64 \mathrm{~kW})$, and amorphous silicon $(2.40 \mathrm{~kW})$ PV panels are analyzed in 2014, in Duzce (Turkey). Efficiency and generated power of PV panels are compared yearly. Solar radiation, ambient temperature, PV panel temperature, and wind measurements are recorded during the test study. Many other works have been conducted to evaluate performance of various PV panels in different locations such as Slovenia [15], Norway [16], Ireland [17], Morocco [18], Brazil [19], Nigeria [20], Jordan [21], Algeria [22], and Croatia [23]. To the best of our knowledge, this is the first work which assesses outdoor performance of four different types of new and 5-year-old PV panels. In order to achieve this, PV panels are installed in Ankara, Turkey, and it is important to select the most efficient PV panel technology to generate electricity efficiently in this location.

There must be a measurement system to measure both weather conditions and power generation capacity of PV panels. In order to measure the generated power of $\mathrm{PV}$ panels, various types of measurement systems have been designed and applied. For instance, Rezk et al. [24] have designed a measurement system based on the DAQ card (NI_USB-6009). In the work, a charge controller with battery unit is used as load, and multicrystalline silicon PV panel is used for test activities. Machacek et al. [25] have implemented a measuring unit (NI_PCI-6023E) and computerbased data acquisition model. A $100 \mathrm{~W}$ PV panel is used to perform its current, voltage, and power measurements. Solar radiation, PV panel temperature, and ambient temperature measurements are also measured. Hammoumi et al. [26] have performed a test study, where a PV panel is connected to a variable load and taking the measurements using current and voltage sensors which are connected to the system. Demirtas et al. [12] have demonstrated a long-term performance measurements of CIS and CdTe PV panels. In this work, measurement data includes direct current (DC) and alternating current (AC), voltage, power, and efficiency. Munoz-Garcia et al. [27] have performed a study to obtain I-V curves of CIS, a-Si, and CdTe PV panel technologies using electronic load, both indoor and outdoor conditions at STC. Digital thermometer and pyranometer are used to record external conditions. Indoor and outdoor performance of this measurement system has been investigated. Kivrak et al. [28] have designed a system to obtain the measurements of four same types of PV panels using MOSFET electronic load based on a 4-channel measurement printed circuit board (PCB), tested outdoor. Polverini et al. [29] have realized an experimental indoor study under STC, to test 70 pcs of polycrystalline silicon PV panel that remained about 20 years outdoor. The aforementioned measurement systems have several drawbacks and limitations such as (1) lack of availability of weather measurement sensors, (2) lack of capability of measuring generated power of many PV panels, (3) lack of accurate measuring power generation under varying weather conditions, (4) lack of sensitivity of measured power, and (5) using costly products and circuit boards.

To address the limitations and drawbacks of the other measurement systems, in this study, multi-photovoltaic panel measurement and analysis system (PPMAS) is designed to 
measure the different types of PV panels installed in Ankara, Turkey. Note that the data is collected for six months from the first of December 2019 until the end of May 2020. The overall system consists of three subsystems which are (1) PV panel measurement subsystem (PPMS), (2) meteorology measurement subsystem (MMS), and (3) data acquisition subsystem (DAS). In the PPMS, the $P_{\max }$ (maximum power) parameter of PV panel is measured. Besides this, other important parameters of the panels are estimated using the measured $P_{\max }$. Moreover, a measurement maximum peak power (MPP) technique is applied in this subsystem to accurately measure the $P_{\max }$. The second subsystem includes different sensors which measure wind speed, wind direction, outdoor temperature, humidity, ambient light, and panel temperatures. In the last subsystem, the parameters which are measured in the other subsystems are stored in a database and displayed in a computer. The overall system is performed with four new and four 5-year-old PV panel technologies which are based on polycrystalline, monocrystalline, copper indium selenide (CIS), and cadmium telluride (CdTe). Thus, performance of power generation of new and old PV panels is experimentally and statistically investigated for the best PV panel evaluation and selection under varying weather conditions in Ankara, Turkey. The main objectives and contributions of this study are as follows:

(1) Multi-photovoltaic panel measurement and analysis system (PPMAS) is designed

(2) Performance of new and old PV panel technologies are assessed and analyzed

(3) Atmospheric measurement subsystem is designed

(4) Eight PV panel technologies are examined for the location of Ankara Province, Turkey.

\section{Designed Multi-Photovoltaic Panel Measurement and Analysis System}

The PPMAS is a system to evaluate power generation capacities of up to eight PV panels in outdoor environment in Ankara, Turkey (see Figure 1). The overall system including eight PV panels and PPMAS is shown in Figure 2.

A block diagram of designed PPMAS is shown in Figure 3. The PPMAS includes three major subsystems, and their working principles are explained with details below.

2.1. Photovoltaic Panel Measurement Subsystem (PPMS). This subsystem is used to obtain $P_{\max }$ (maximum power) value of each PV panel in each 1000 milliseconds using MOSFET electronic load. The $P_{\max }$ is an important parameter because it is used to evaluate the performances of used PV panels. Moreover, this parameter has also been used in many studies to assess the performance of PV panels [12$15,19,22,30,31]$. Other important parameters of PV panels which are $V_{\mathrm{mp}}$ (voltage at maximum power), $I_{\mathrm{mp}}$ (current at maximum power), $I_{\mathrm{sc}}$ (short circuit current), and $V_{\text {oc }}$ (open circuit voltage) are needed to be obtained or estimated. In order to estimate these parameters, the

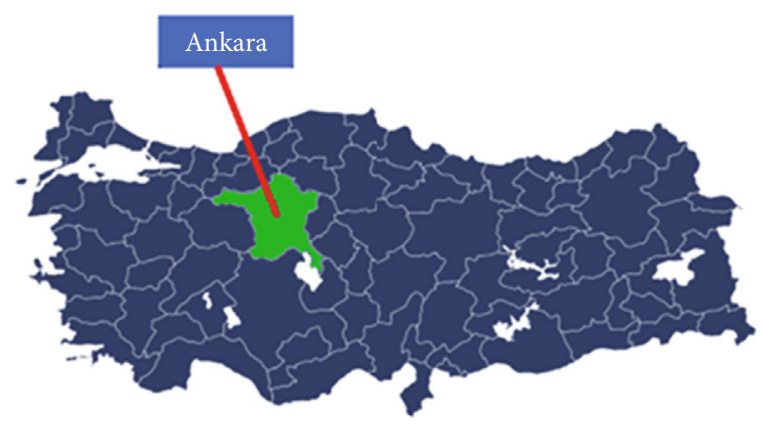

Figure 1: Location of Ankara, Turkey.

measured $P_{\max }$ is used in equations (1) and (2) where FF is fill factor.

$$
\mathrm{FF}=\frac{V_{\mathrm{mp}} \cdot I_{\mathrm{mp}}}{V_{\mathrm{oc}} \cdot I_{\mathrm{sc}}}
$$

After modification of the equation (1), the maximum power $P_{\max }$ is estimated using the new equation as follows:

$$
\text { FF. } V_{\mathrm{oc}} \cdot I_{\mathrm{sc}}=V_{\mathrm{mp}} \cdot I_{\mathrm{mp}}=P_{\mathrm{max}} \cdot
$$

Note that, in the system, it is important to accurately obtain the $P_{\max }$ because it is used to estimate the other parameters of PV panels such as efficiency. To achieve this, it is necessary to increase sensitivity of the PPMS. In order to increase the sensitivity of the PPMS, the measurement of maximum peak power (MPP) technique is applied in PPMS subsystem $[27,28]$. Furthermore, PPMS can measure $P_{\max }$ of up to eight PV panels and estimate other parameters of these panels, separately.

Efficiency of a PV panel is evaluated by the ratio of amount of energy generated by the PV panel to the amount of solar radiation reflected in its surface area [14]. The efficiency is a useful metric that enables comparison of PV panels which have different nominal power outputs with different surface areas. Efficiency of a PV panel is expressed in percentage. In order to estimate efficiency of the PV panels, the following equation is used:

$$
\eta_{\text {daily }}=\left(\frac{P_{\text {daily }}}{P V_{\text {area }} \cdot H_{\text {daily }}}\right) \cdot 100 .
$$

where $\eta_{\text {daily }}$ represents the average daily PV panel efficiency in percentage (\%), $P_{\text {daily }}$ is the daily average power output in Watt, $H_{\text {daily }}$ is the amount of daily solar radiation in Watt $/ \mathrm{m}^{2}$, and $P V_{\text {area }}$ symbolizes the surface area of PV panel $\left(\mathrm{m}^{2}\right)$. Monthly average PV panel efficiency can be described in the equation (4) as follows, where $t$ is number of days in a month:

$$
\eta_{\text {monthly }}=\left(\frac{\sum_{i=1}^{t} P_{(\text {daily }) i}}{P V_{\text {area }} \cdot \sum_{i=1}^{t} H_{(\text {daily }) i}}\right) \cdot 100 .
$$




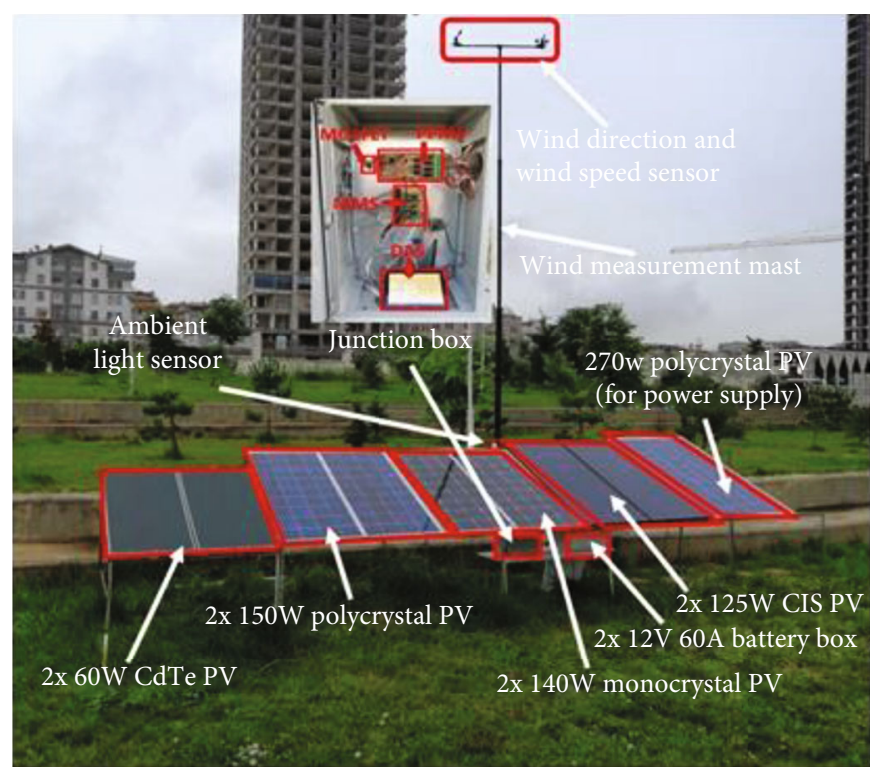

FIgURE 2: PPMAS system including PV panels and wind measurement mast.

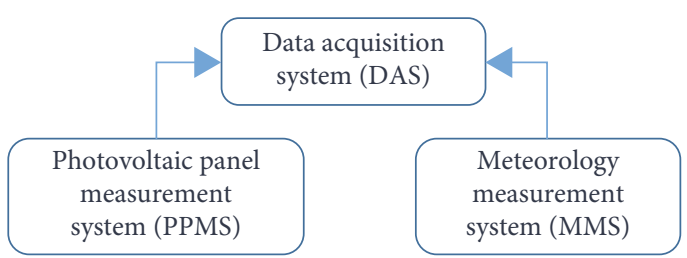

FIGURE 3: Block diagram of photovoltaic panel measurement and analysis system (PPMAS).

The PPMS consists five main blocks which are (1) power supply block, (2) PPMS PCB block, (3) relay and switching block, (4) measurement block, and (5) data transmitting block. Power supply block contains $12 \mathrm{~V} / 2 \mathrm{~A}$ DC-DC converter which is connected to the input of the PPMS as a power supply. PPMS PCB block (see Figures 4(a) and 4(b)) is an interface of microcontroller with relay and switching block, measurement block, and data transmitting block. PPMS has PV panel connection pins and one UART headers for data transmitting block interfacing. In this block, the microcontroller manages PPMS measurement activities. Relay and switching block contains 7 relays which are used to switch the PV panels, and these relays in this block are activated one by one using the microcontroller. Measurement block is used to measure the generated power of the PV panels using MOSFET electronic load (see Figure 5). ACS-712/30A is connected on the serial to drain the leg of the MOSFET to measure the current. R_6 and RV_2 voltage dividers are connected parallel to drain and source legs of the MOSFET to measure the voltage. Voltage $\left(V_{\text {sense }}\right)$ and current $\left(I_{\text {sense }}\right)$ measurement pins are connected to analog inputs of microcontroller (see Figure 5). Data transmitting block is used for communication purposes between PPMS and DAS computer reliably.

The microcontroller in the PPMS is connected to the seven relays, and each relay is connected to a different PV panel as shown in Figure 5. The purpose of using microcon- troller is to switch each relay to activate related PV panel in each 1000 milliseconds, sequentially. Thus, the generated power of the activated PV panel is measured using MOSFET. For instance, as depicted in Figure 5, the microcontroller activates the fourth relay which is connected to the $140 \mathrm{~W}$ monocrystal PV panel, and MOSFET is used to measure the generated power $P_{\max }$. After 1000 milliseconds, the fifth relay is switched by the microcontroller to measure the generated power of $150 \mathrm{~W}$ polycrystal PV panel and so on. The measured and estimated PV panel data parameters are transmitted to the DAS subsystem using serial communication continuously.

2.1.1. MOSFET as an Electronic Load and $I-V$ Characterization of a PV Panel. One of the most significant parameter of a PV panel is the I-V curve, which includes PV panel performance metrics such as efficiency, $\eta$; open circuit voltage, $V_{\mathrm{oc}}$; short circuit current, $I_{\mathrm{sc}}$; maximum power, $P_{\max }$; voltage at maximum power point, $V_{\mathrm{mp}}$; and current at maximum power, $I_{\mathrm{mp}}$ [32]. In order to achieve the I-V curve of a PV panel, it is required to control the current generated by a PV panel from zero current point to short circuit point [33]. To control the current and to obtain the I-V curve of a PV panel, MOSFET can be used as an electronic load in the designed PPMS subsystem.

Drain and source of a MOSFET may behave as a variable resistor, when there is a voltage difference on gate and source pins, such that when gate and source voltage difference is high, drain and source behave as low resistance (can be assumed short circuit), and when the gate and source voltage difference is low, drain and source behave as high resistance (can be assumed open circuit) [34]. By utilizing this feature of MOSFET, I-V characteristics of a PV panel can be extracted.

In our study, microcontroller drives the MOSFET to evaluate all current and voltage values of a PV panel from open circuit to short circuit point, in a measurement period 


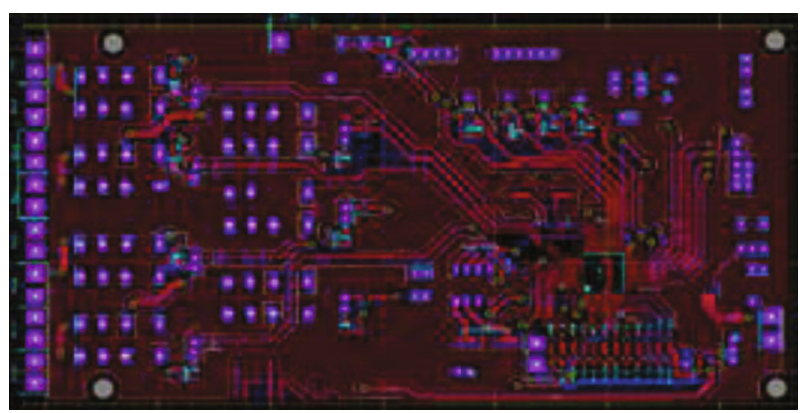

(a)

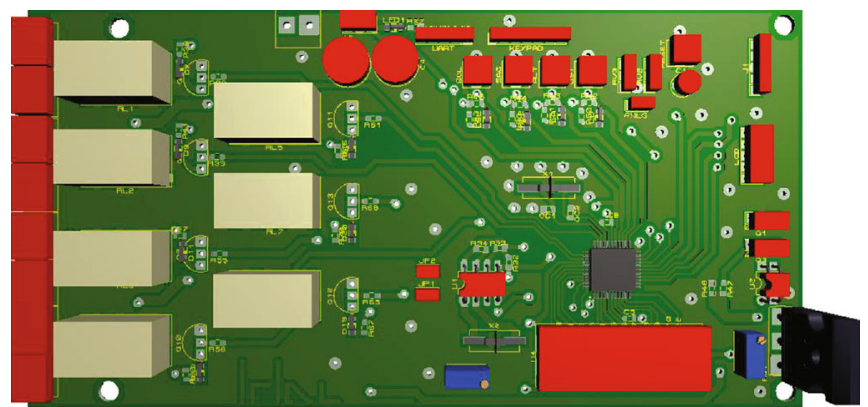

(b)

FIgure 4: (a) Pin connections between PPMS and PV panels. (b) 3D view of connections between PPMS and PV panels.

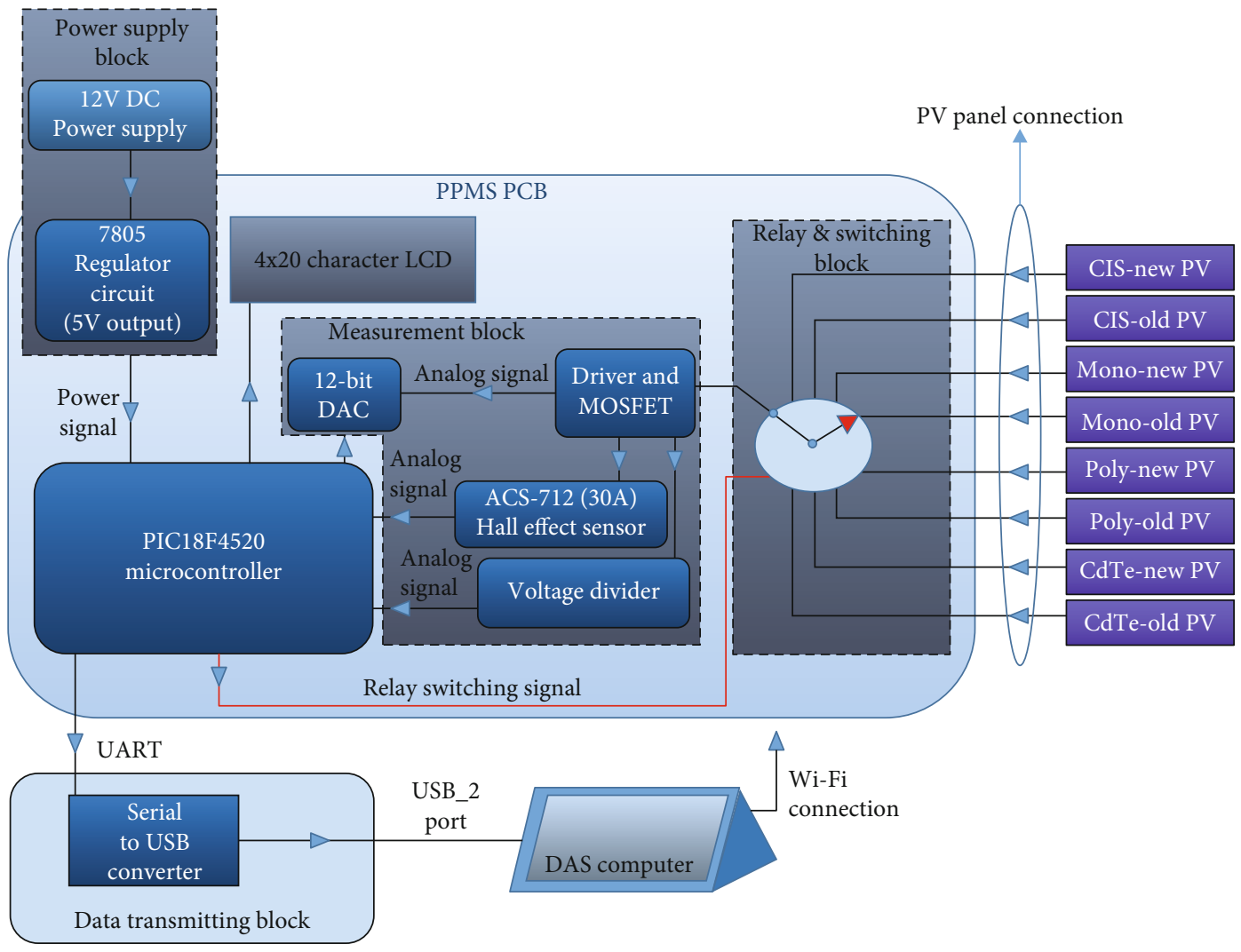

Figure 5: Photovoltaic panel measurement subsystem (PPMS).

(1000 milliseconds). During one measurement period, PPMS microcontroller observes the highest power point recorded in Watts, which is called $P_{\max }$. After finding $P_{\max }$, its components are recorded as $I_{\mathrm{mp}}$ and $V_{\mathrm{mp}}$.

2.2. Meteorology Measurement Subsystem (MMS). The main purpose of using MMS subsystem is to measure the meteorological parameters which are ambient temperature, humidity, ambient light, wind speed, wind direction, and PV panel temperatures. These parameters are significantly important because performance of power generation of PV panels is depending on these parameters $[30,35,36]$. In this subsystem, the parameters are measured at each second from 5:00 a.m. until 9:00 p.m. In order to achieve these measurements, the MMS consists four main blocks as shown in Figure 6. In the MMS PCB block, a microcontroller is employed to measure the meteorological parameters and interconnected with power supply block, sensor array block, and data transmitting block. For instance, the pin connections between MMS PCB block and power supply block are illustrated in Figures 7(a) and 7(b). In the sensor array block, twelve meteorological sensors which are DHT-22 temperature and humidity sensor, Max44009 ambient light sensor, wind speed and direction sensors, and 8 pcs DS18B20 PV panel temperature sensors have been used to understand and measure both atmospheric conditions and temperature of PV panels. The power supply block is used to energize the MMS PCB block and sensor array block. Thus, the components in these 


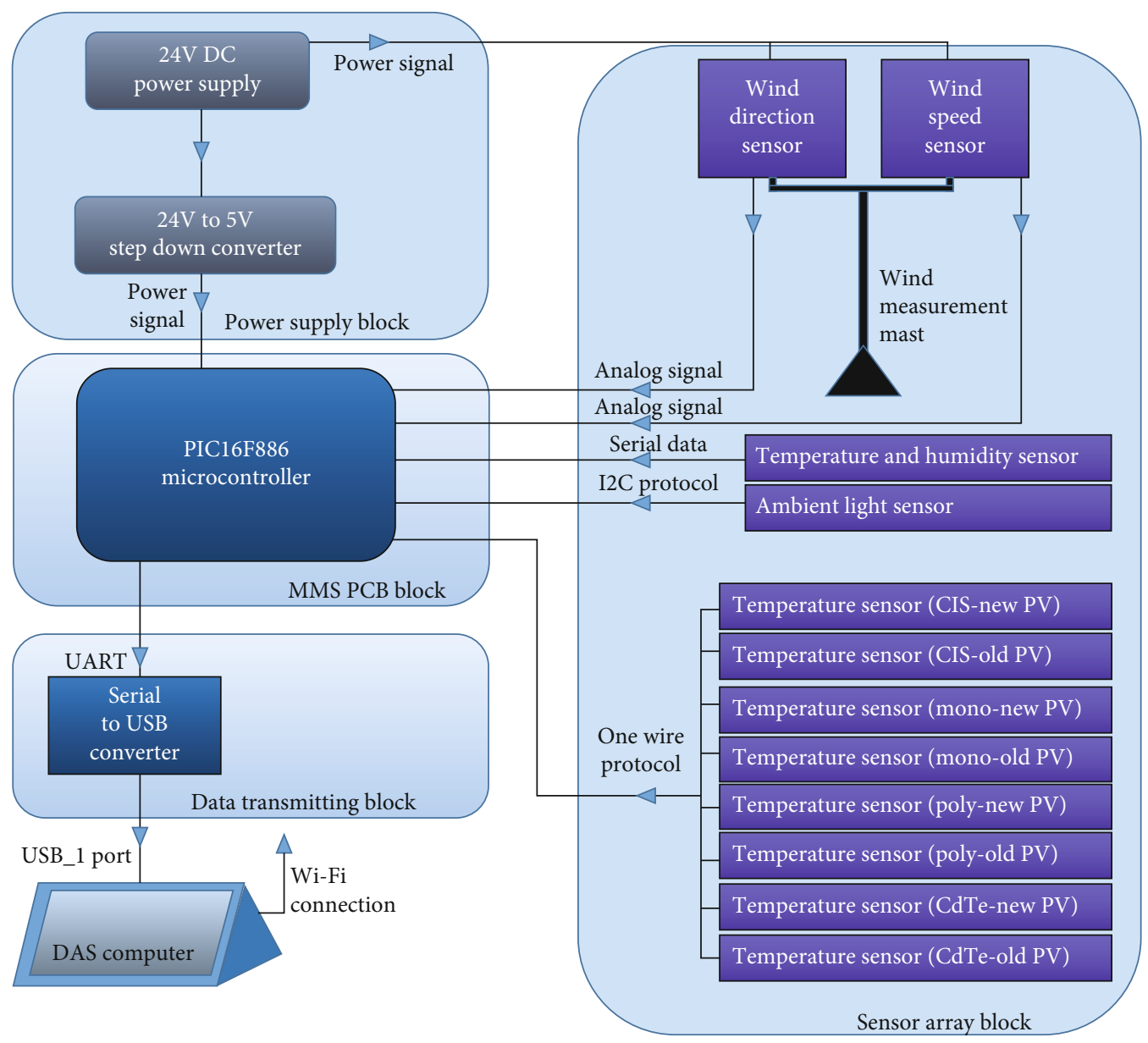

FIGURE 6: Meteorology measurement system (MMS).

blocks can work without any electrical problem. In this subsystem, data transmitting block is used to transmit the measured meteorological data via connected cable to a data acquisition system (DAS) computer for storing data. Finally, the recorded data in the DAS computer is transmitted to the personal computer for analyzing the purposes when the user requests this data from the DAS computer.

2.3. Data Acquisition Subsystem (DAS). The last subsystem of PPMAS system which is illustrated in Figure 8 manages the real-time data monitoring and data storage activities. In order to achieve this, both measured and estimated parameters in the PPMS and the MMS are sent to DAS computer via connected communication cables. In the last subsystem, the parameters which are measured in the other subsystems are stored in a database in DAS computer, and the recorded data can be transmitted remotely to a personal computer for analyzing and data displaying purposes continuously if a user requests data from DAS. Note that DAS computer has the capability to store and monitor all the parameters of all PV panels which are connected to the PPMS as well as the meteorological parameter measurements obtained in MMS. Besides, DAS has a storage capacity to record a total of 50 years of measurement data in continuous operation.
2.4. One-Cycle Operation of PPMS Subsystem. Measurement circuit of PPMS is depicted in Figure 9. As shown in Figure 5, a microcontroller in the PPMS selects the related relay combinations to activate mono-old PV connection to Hall effect sensor and then to drain MOSFET to measure current pass through in it when the switching signal comes to the gate of MOSFET by the 12-bit DAC signal. DAC signal is generated through the R-2R ladder circuit from the digital outputs of the microcontroller. DAC signal enters the optoisolator to switch $12 \mathrm{~V}$ to a totem-pole circuit. The totem-pole circuit is used to drive MOSFET in the linear region. The R_1 potentiometer is an adjustable resistor to adjust the threshold level in terms of voltage for the optoisolator. At the same time PV panel (mono-old PV) connection comes to (IP+) pin of Hall effect sensor (ACS-712/30A) serially (see Figure 5) which is used to calculate the current of (mono-old PV) PV panel. (IP-) pin of the Hall effect sensor goes to the MOSFET's drain pin, so that the current flows from the drain to source by using MOSFET as electronic load. The $I_{\text {sense }}$ output pin of the Hall effect sensor goes to the analog input of the microcontroller to measure the current of the PV panel (mono-old PV). Also the $V_{\text {sense }}$ pin goes to another analog input channel of teh microcontroller to measure the voltage of the PV panel (mono-old PV), where 


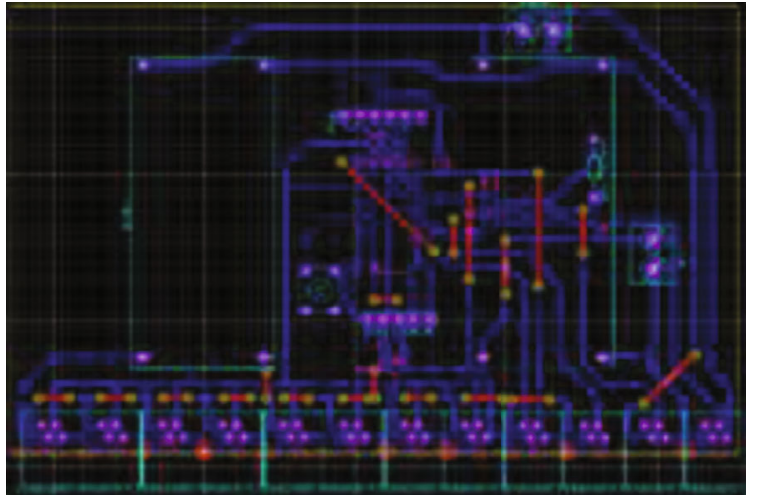

(a)

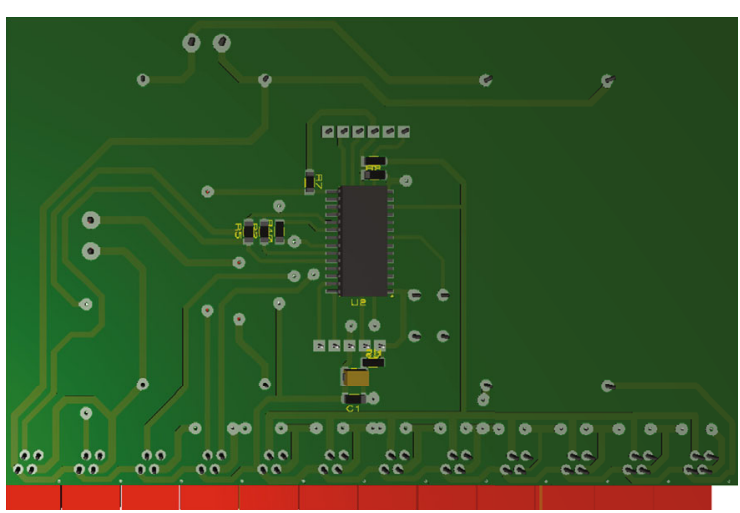

(b)

FIGURE 7: (a) Pin connections between MMS PCB block and power supply block. (b) 3D view of pin connections between MMS PCB block and power supply block.

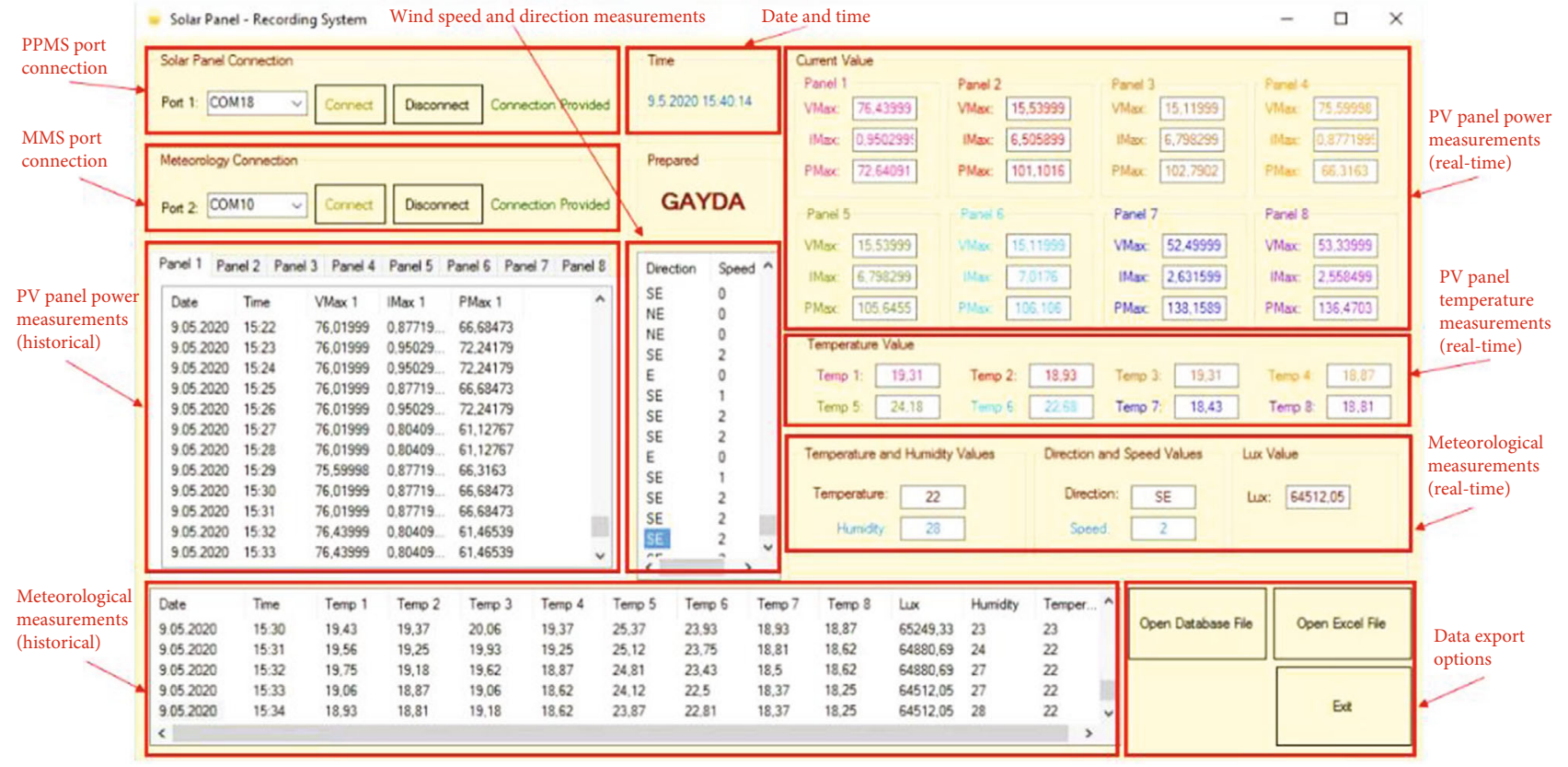

FIgURE 8: View of data monitoring interface in DAS computer.

R_6 and RV_2 are used as voltage divider. Measurement calibration is done by RV_2 potentiometer. Microcontroller measures and stores the generated power of PV panel (mono-old PV), with respect to voltage and current measurements $\left(P_{\max }=V_{\mathrm{mp}} \times I_{\mathrm{mp}}\right)$ continuously during measurement cycle, which is 1000 milliseconds. The microcontroller assigns the highest power value as $P_{\max }$, among the stored power values. The microcontroller determines the current and voltage values that form the $P_{\max }$, as $I_{\mathrm{mp}}$ and $V_{\mathrm{mp}}$, respectively. After $P_{\max }$ evaluation of PV panel (Mono-old PV), it means measurements are completed for one cycle. All other PV panel (CIS-new, CIS-old, Mono-new, Poly-new, Poly-old, CdTenew, and CdTe-old) connections are switched to the MOSFET in a sequence with respect to a switching strategy to obtain $V_{\mathrm{mp}}, I_{\mathrm{mp}}$, and $P_{\max }$ of each PV panel with the same manner.

\section{Results and Discussion}

In the scope of this experimental study, it aimed at analyzing and comparing the power generation performances of polycrystalline, monocrystalline, CIS, and CdTe PV panel pairs, within a specified time, under different weather conditions in Ankara, Turkey. Besides this, the generated power and temperatures of $\mathrm{PV}$ panels as well as atmospheric parameters are measured and stored using the developed system PPMAS. In [37], the inclination angles of different locations are examined and discussed, and for Ankara Province, it is about $30^{\circ}$. Therefore, in this study, the inclination angle of the PV panels is set to $30^{\circ}$ and facing to the south to get sunlight better based on the location where the PV panels are installed. Furthermore, measurements obtained by PV panels 


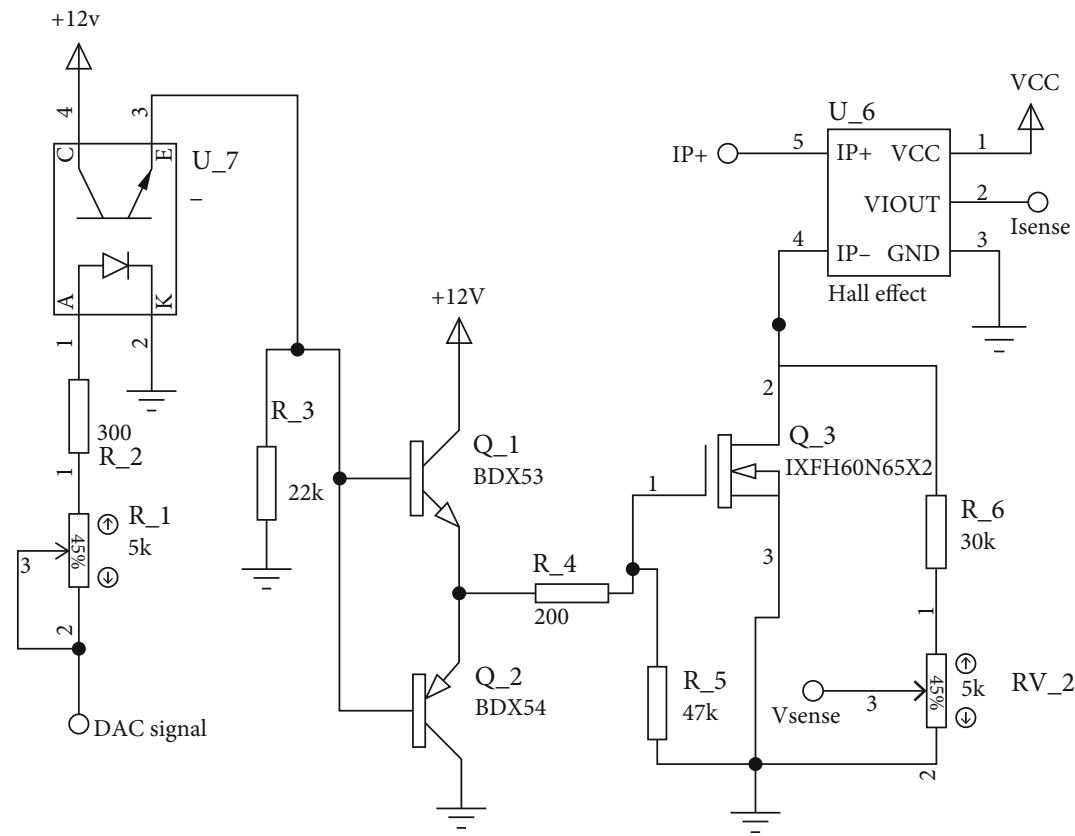

Figure 9: IXFH60N65X2 MOSFET and measurement circuit for PPMS PCB.

TABLE 1: Characteristics of new and 5-year-old PV panel technologies used in the study.

\begin{tabular}{|c|c|c|c|c|c|}
\hline PV panel type & $\begin{array}{c}P_{\text {nom }} \\
\text { (nominal power) }\end{array}$ & $\begin{array}{c}V_{\mathrm{oc}} \\
\text { (open circuit voltage) }\end{array}$ & $\begin{array}{c}I_{\mathrm{sc}} \\
\text { (short circuit current) }\end{array}$ & $\begin{array}{c}V_{\mathrm{mpp}} \\
\text { (voltage at MPP) }\end{array}$ & $\begin{array}{c}I_{\mathrm{mpp}} \\
\text { (current at MPP) }\end{array}$ \\
\hline $\begin{array}{l}\text { Monocrystalline } \\
\text { (mono-new) }\end{array}$ & $140 \mathrm{Wp}( \pm 3 \%)$ & $21.5 \mathrm{~V}$ & $8.33 \mathrm{~A}$ & $18.0 \mathrm{~V}$ & $7.78 \mathrm{~A}$ \\
\hline $\begin{array}{l}\text { Monocrystalline } \\
\text { (mono-old) }\end{array}$ & $140 \mathrm{Wp}( \pm 3 \%)$ & $21.5 \mathrm{~V}$ & $8.33 \mathrm{~A}$ & $18.0 \mathrm{~V}$ & $7.78 \mathrm{~A}$ \\
\hline $\begin{array}{l}\text { Polycrystalline } \\
\text { (poly-new) }\end{array}$ & $150 \mathrm{Wp}( \pm 3 \%)$ & $22.4 \mathrm{~V}$ & $8.46 \mathrm{~A}$ & $18.2 \mathrm{~V}$ & $7.95 \mathrm{~A}$ \\
\hline $\begin{array}{l}\text { Polycrystalline } \\
\text { (poly-old) }\end{array}$ & $150 \mathrm{Wp}( \pm 3 \%)$ & $22.4 \mathrm{~V}$ & $8.46 \mathrm{~A}$ & $18.2 \mathrm{~V}$ & $7.95 \mathrm{~A}$ \\
\hline CIS (CIS-new) & $125 \mathrm{Wp}( \pm 4 \%)$ & $59.3 \mathrm{~V}$ & $3.22 \mathrm{~A}$ & $44.0 \mathrm{~V}$ & $2.84 \mathrm{~A}$ \\
\hline CIS (CIS-old) & $125 \mathrm{Wp}( \pm 4 \%)$ & $59.3 \mathrm{~V}$ & $3.22 \mathrm{~A}$ & $44.0 \mathrm{~V}$ & $2.84 \mathrm{~A}$ \\
\hline CdTe (CdTe-new) & $60 \mathrm{Wp}( \pm 5 \%)$ & $89.7 \mathrm{~V}$ & $1.23 \mathrm{~A}$ & $62.2 \mathrm{~V}$ & $0.99 \mathrm{~A}$ \\
\hline CdTe (CdTe-old) & $60 \mathrm{Wp}( \pm 5 \%)$ & $89.7 \mathrm{~V}$ & $1.23 \mathrm{~A}$ & $62.2 \mathrm{~V}$ & $0.99 \mathrm{~A}$ \\
\hline
\end{tabular}

Table 2: Climate data for Ankara Province (Turkey) between the years of 1927 and 2019 [39].

\begin{tabular}{|c|c|c|c|c|c|c|c|c|c|c|c|c|c|}
\hline & Jan & Feb & Mar & Apr & May & Jun & Jul & Aug & Sep & Oct & Nov & Dec & Yearly \\
\hline Ave. temp. $\left({ }^{\circ} \mathrm{C}\right)$ & 0.1 & 1.6 & 5.7 & 11.2 & 16.0 & 19.9 & 23.3 & 23.3 & 18.8 & 13.1 & 7.2 & 2.4 & 11.9 \\
\hline Ave. max. temp. $\left({ }^{\circ} \mathrm{C}\right)$ & 4.1 & 6.4 & 11.4 & 17.3 & 22.3 & 26.6 & 30.2 & 30.4 & 25.9 & 19.9 & 13.0 & 6.4 & 17.8 \\
\hline Ave. min. temp. $\left({ }^{\circ} \mathrm{C}\right)$ & -3.2 & -2.3 & 0.6 & 5.3 & 9.6 & 12.9 & 15.8 & 15.9 & 11.7 & 7.0 & 2.5 & -0.8 & 6.3 \\
\hline Ave. sunshine duration (hour) & 2.6 & 3.8 & 5.1 & 6.6 & 8.5 & 10.0 & 11.3 & 10.7 & 9.2 & 6.7 & 4.5 & 2.5 & 81.5 \\
\hline Ave. rainy days & 12.3 & 11.2 & 10.7 & 11.2 & 12.3 & 8.7 & 3.6 & 2.7 & 4.0 & 6.9 & 8.2 & 11.7 & 103.5 \\
\hline Ave. total monthly rainfall $(\mathrm{mm})$ & 40.2 & 35.1 & 39.1 & 42.5 & 51.5 & 34.4 & 14.3 & 12.7 & 18.0 & 27.7 & 31.5 & 44.9 & 391.9 \\
\hline
\end{tabular}

and meteorological sensors have been collected at one-second interval for six months between the first of December 2019 and 30 May 2020. The measured values which are $I_{\mathrm{mp}}, V_{\mathrm{mp}}$, and $P_{\max }$ in DC for each PV panel and wind speed and direction, ambient temperature, humidity, ambient light, and PV panel temperatures have been stored to analyze the 


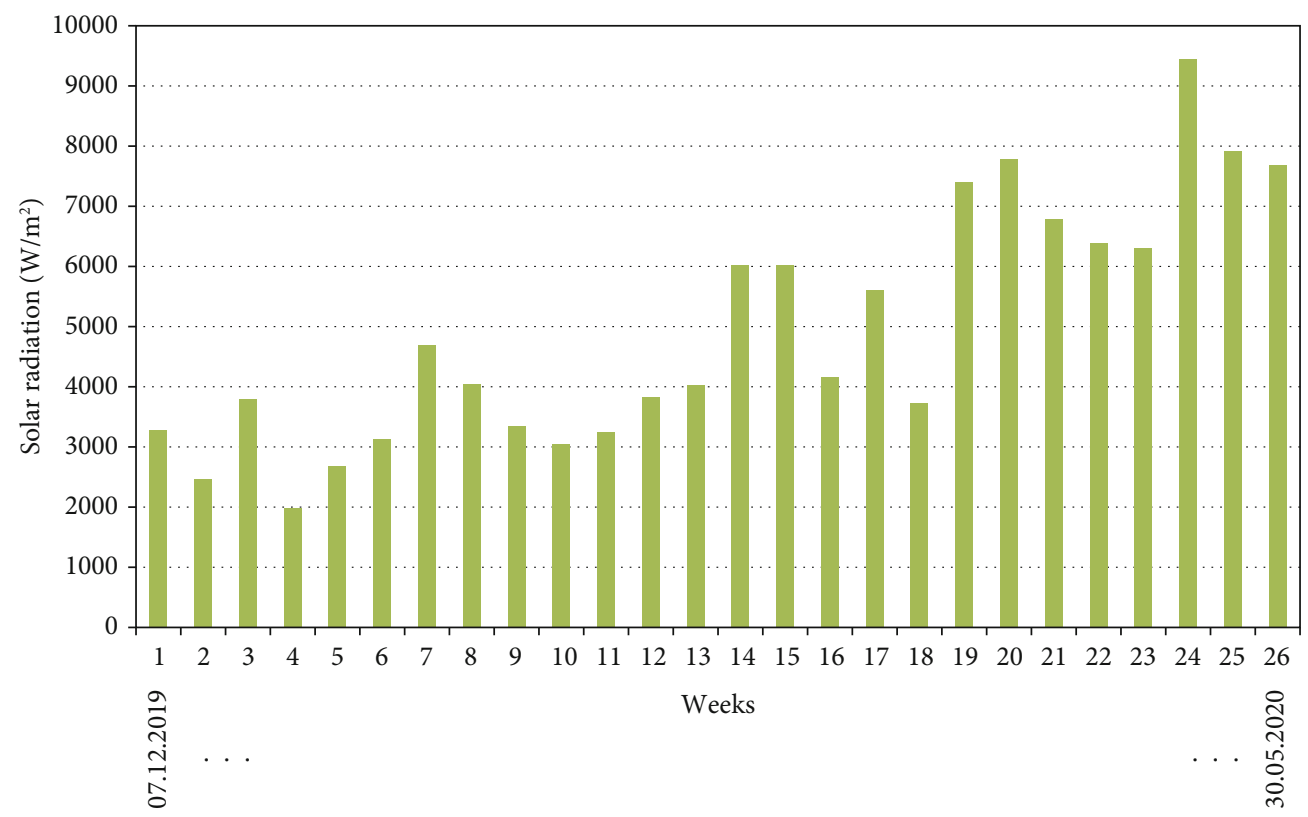

Figure 10: Weekly average results of solar radiation between December 2019 and May 2020 in Ankara.

performance of PV panels as well as understand the reliability of the designed PPMAS system.

3.1. Verification of Designed PPMAS System. The designed subsystems which are MMS and PPMS in the PPMAS system are tested and calibrated in a laboratory environment to improve the measurement accuracy. Three different devices which are the vantage pro2 wireless meteorology station, Tt-Technic RXN305D2 power supply, Cem DT-1301 luxmeter, Tektronix MSO 2024B oscilloscope, and Fluke-289 multimeter are selected for calibrating MMS and PPMS since they are widely used and perform measurements accurately.

3.1.1. Calibration of MMS. It is significantly important to calibrate the MMS subsystem to get the atmospheric measurements accurately. In order to achieve this, the vantage pro2 wireless meteorology station is used to calibrate MMS sensor measurements. The vantage pro2 wireless meteorology station which has ambient temperature, humidity, wind speed, and direction sensors is installed next to the MMS subsystem. The MMS subsystem is calibrated according to the measurements obtained using the vantage pro2 meteorology station. Thus, the atmospheric values are accurately measured after calibrating the MMS subsystem.

Moreover, the Max44009 sensor is used in the MMS to estimate solar radiation, where it is installed to get the illuminance of the sun. Note that the angle of the sensor and PV panels is the same, and the sensor is calibrated using Cem DT-1301 Luxmeter. The measurement unit is in Lux. In order to convert Lux to $\mathrm{W} / \mathrm{m}^{2}$, the measured value is multiplied by 0.00833 [38].

3.1.2. Calibration of PPMS. Another important subsystem in the PPMAS system is PPMS subsystem which is needed to be calibrated to measure the generated power of PV panels accurately. To achieve this, Tektronix MSO 2024B oscilloscope, Fluke-289 multimeter, and Tt-Technic RXN305D2 power supply with $0-30 \mathrm{~V} 0-5 \mathrm{~A}$ are used to calibrate the PPMS subsystem. As a result, the calibrated PPMS subsystem can measure the generated power of PV panels accurately.

3.2. PV Panels. In this study, new and 5-year-old PV panel technologies have been used, and the characteristics of these PV panels are tabulated in Table 1. Thus, in this experiment, totally eight PV panels are used which are new and 5-yearold monocrystalline with $140 \mathrm{~W}$, new and 5-year-old CIS with $125 \mathrm{~W}$, new and 5-year-old polycrystalline with $150 \mathrm{~W}$, and new and 5-year-old CdTe with $60 \mathrm{~W}$. In order to supply power requirement of the experimental system, a solar power station is used. Power station consists one $270 \mathrm{~W}$ polycrystalline PV panel, two 12 V/60A batteries as shown in Figure 2. Thus, the PPMAS works properly under insufficient sunlight situations (i.e., cloudy day) up to 3 days.

3.3. Climate Data in Ankara Province. The climate data between the years of 1927 and 2019 in Ankara Province, Turkey, is presented in Table 2 [39]. According to the climate data, the highest average temperature is obtained in July and August with $23.3^{\circ} \mathrm{C}$. Moreover, the greatest average maximum and the least minimum temperatures between 1927 and 2019 are estimated with $30.4^{\circ} \mathrm{C}$ in August and with $0.1^{\circ} \mathrm{C}$ in January, respectively. The longest and shortest average sunshine durations are 11.3 hours in July and 2.5 hours in December, respectively. Furthermore, the highest amount of average monthly rainfall is observed $44.9 \mathrm{~mm}$ in December.

3.4. Solar Radiation. Solar radiation is significantly important parameter which is used to calculate the efficiencies of the PV panels. Figure 10 shows weekly average results of solar radiation. This data is obtained using the MMS sensor box in the 


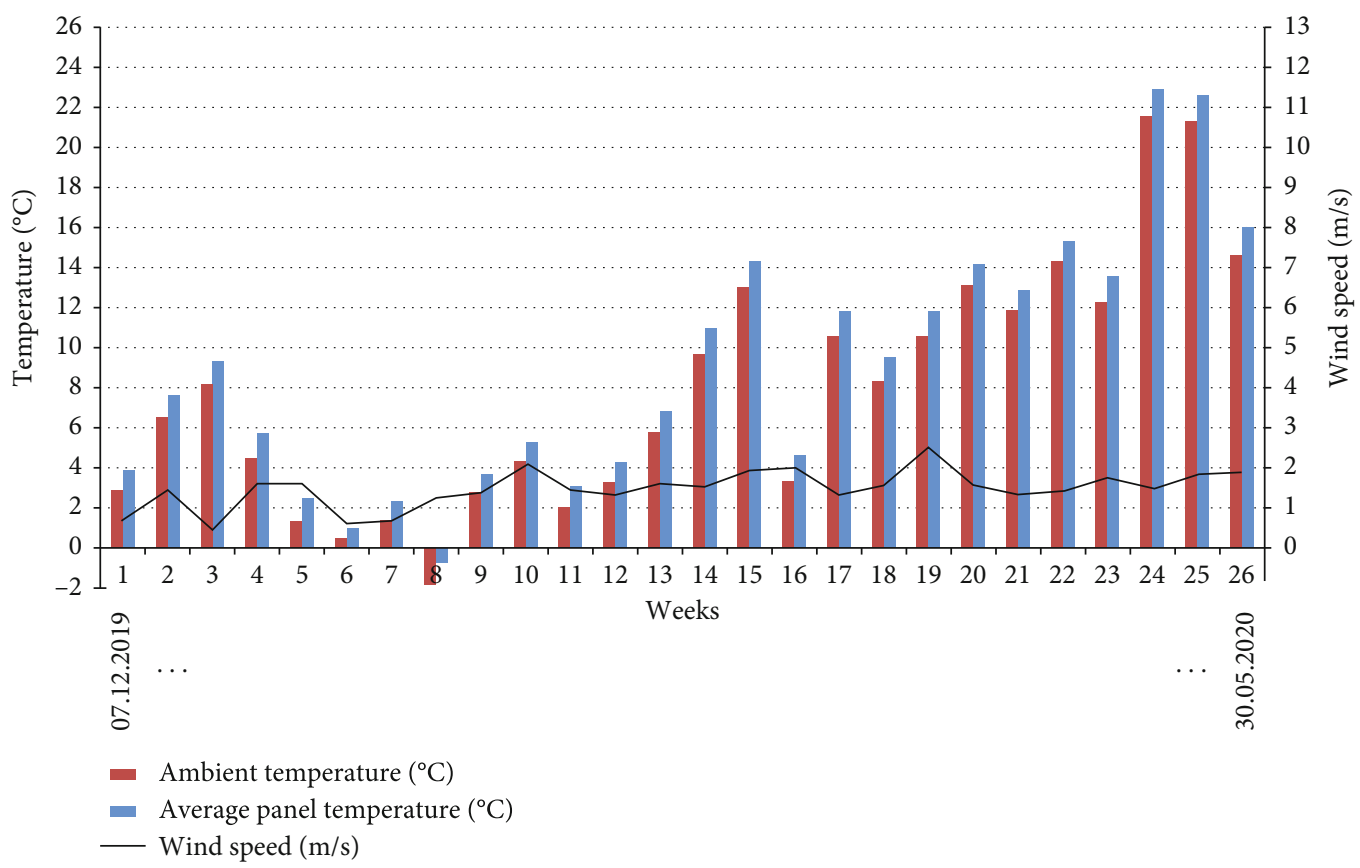

FIGURE 11: Weekly average ambient temperature, panel temperature, and wind speed between December 2019 and May 2020 in Ankara.

designed PPMAS system for six months in Ankara, Turkey. In Figure 10, the first week average result is obtained between 1 st of December 2019 and 7th of December 2019, and the week 26 represents the date of 30st of May 2020. According to the results, the least and highest average solar radiation results are estimated with $1968 \mathrm{Wm}^{2}$ in week 4 and $9459 \mathrm{Wm}^{2}$ in week 24, respectively. As a result, these estimations clearly demonstrate that the lowest solar radiation is obtained in December 2019, and the highest solar radiation is obtained in May 2020. There can be different reasons to get variety of weekly solar radiation results such as weather conditions, angle of sunlight, and location of Ankara [40].

3.5. Effect of Atmospheric Variations on PV Panel Temperatures. Figure 11 depicts the average weekly atmospheric temperature, wind speed, and PV panel temperatures for six months between December 2019 and May 2020. These results show that PV panel temperature depends on ambient temperature. For instance, in week 15, the average weekly temperature is $13.05^{\circ} \mathrm{C}$, and the average of PV panel temperatures is increased by $1.25^{\circ} \mathrm{C}$ which becomes $14.30^{\circ} \mathrm{C}$, and in week 4 , the average weekly temperature is $4.50^{\circ} \mathrm{C}$, and the average of PV panel temperatures is $5.73^{\circ} \mathrm{C}$. Moreover, based on the six-month measurement, the estimated average temperature is $7.88^{\circ} \mathrm{C}$, and the average of PV panel temperatures is $9.06^{\circ} \mathrm{C}$. According to the results in Figure 11, the least and highest average temperatures are measured with $-1.78^{\circ} \mathrm{C}$ in week 8 and with $21.60^{\circ} \mathrm{C}$ in week 24 , respectively. Moreover, these results clarify that May is the month with the highest daily average temperature. However, January is the lowest daily average temperature. Furthermore, wind speed is low and nearly constant all the months between December and May in Ankara. The average wind speed of these six months is $2.93 \mathrm{~m} / \mathrm{s}$ which indicates that Ankara is not a windy city.
3.6. Performance Assessment of Different PV Panels for Power Generation. Four different PV panel technologies which are polycrystalline-based, monocrystalline-based, CIS-based, and CdTe-based have been used for performance assessment. Besides this, each PV technology has one new and one 5-yearold PV panel. Thus, the performance of new PV panels and 5-year-old PV panels is evaluated. The generated power of each PV panel is measured within a specified time period under the same outdoor conditions in Ankara. The measured powers of eight PV panels are stored in the designed PPMAS system.

Figure 12 illustrates weekly average power generated by new and 5-year-old PV panels between December 2019 and May 2020. Based on these results, all PV panels generate maximum power between 9.05.2020 and 16.05.2020 and the lowest power between 21.02.2020 and 28.02.2020. Besides this, these results show that the new PV panel technologies provide better power generation performance than the 5year-old PV panel technologies in all the weeks. For instance, between 14.12.2019 and 21.12.2019, mono-new and monoold generate daily average of $327 \mathrm{Wh}$ and $316 \mathrm{Wh}$, respectively, and CIS-new generates a daily average of 15 Wh more than CIS-old. In terms of power generation performance, mono-new provides $3.10 \%$ better performance than monoold, poly-new provides $3.34 \%$ better performance than poly-old, CIS-new provides $5.53 \%$ better performance than CIS-old, and CdTe-new provides $6.97 \%$ better performance than CdTe-old. These results indicate that CdTe PV panel is degraded more than the other PV panel technologies. There can be many factors which may affect the performance of PV panels, and these factors are discussed in [31].

Figures 13(a) and 13(b) depict monthly panel efficiencies of new and 5-year-old PV panels, respectively. Note that monthly efficiencies of PV panels are calculated according to the formula given in equation (4). The results in Figure 13(a) 


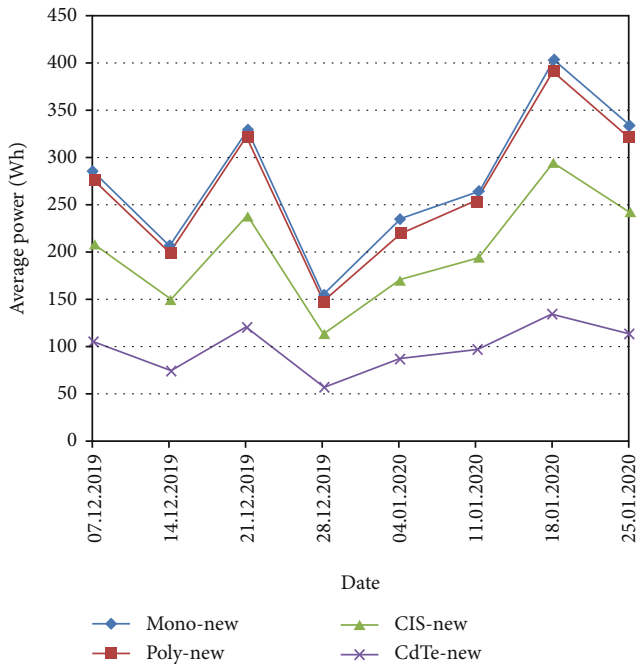

(a)

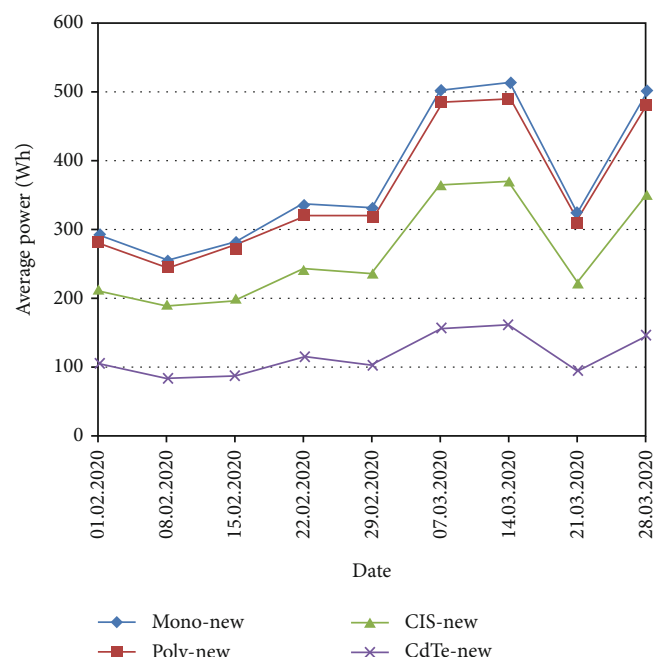

(c)

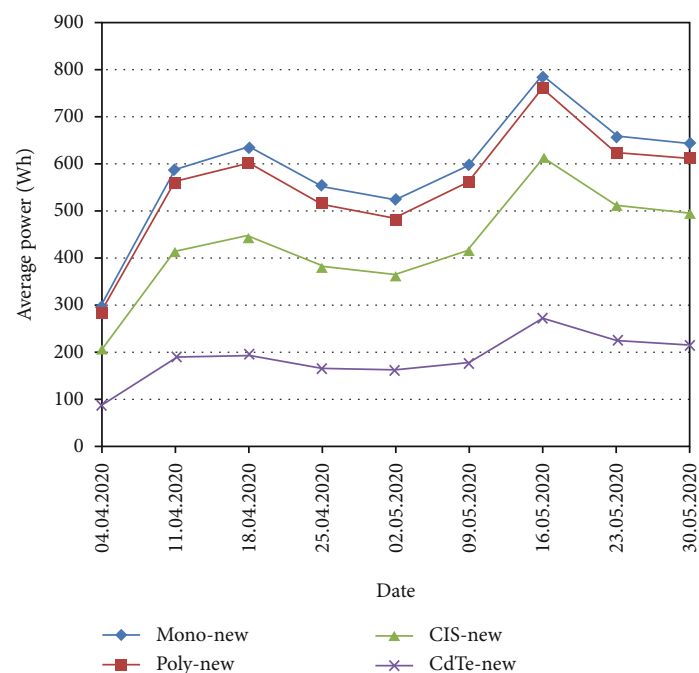

(e)

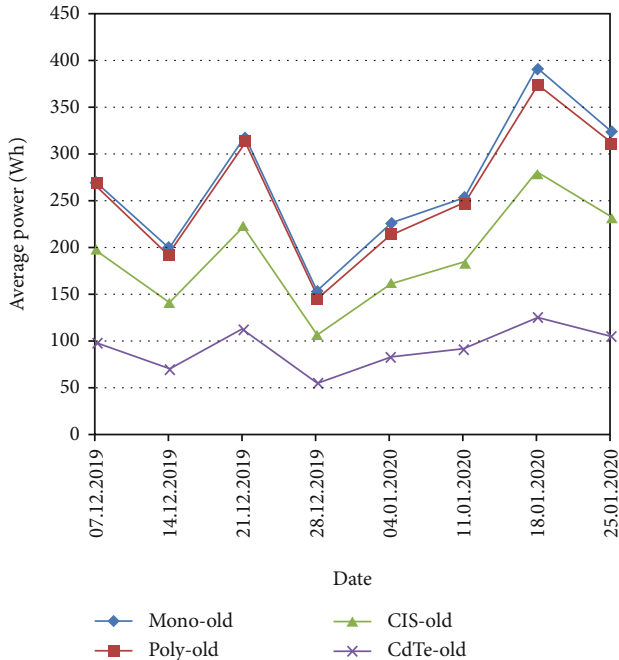

(b)

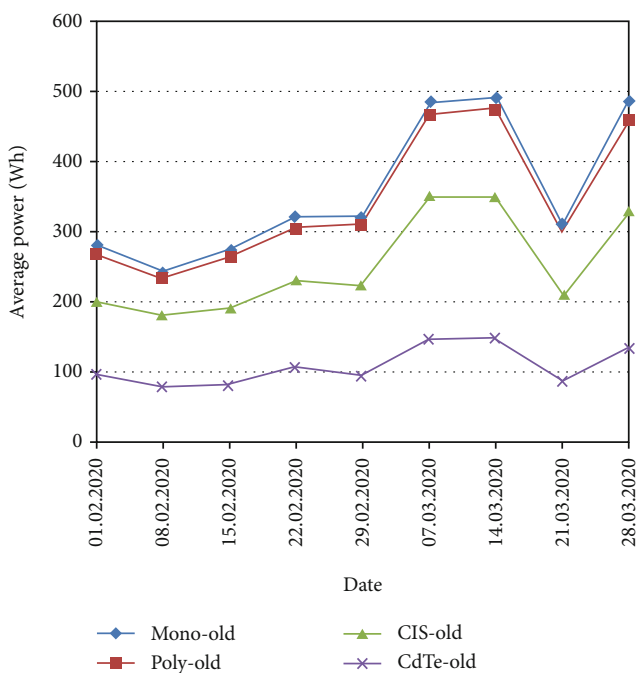

(d)

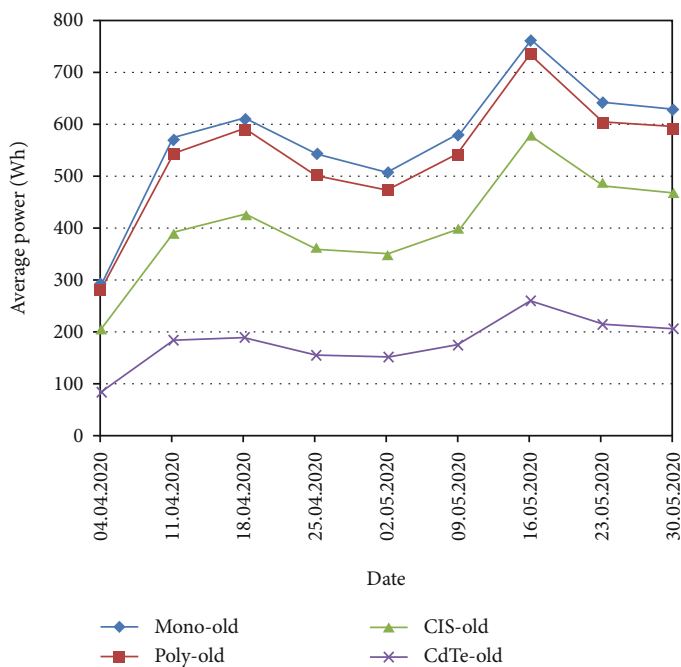

(f)

Figure 12: Weekly average power generated by new and old PV panels. (a, b) December and January. (c, d) February and March. (e, f) April and May. 


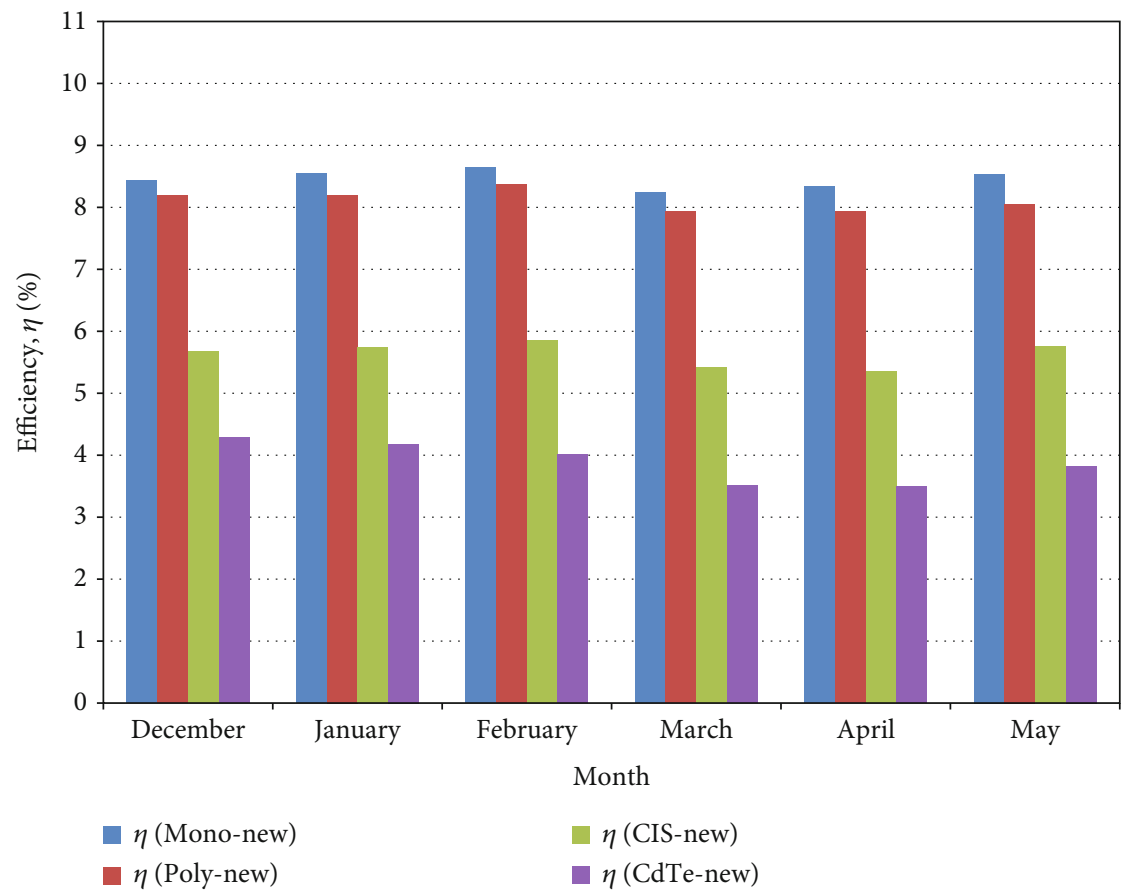

(a)

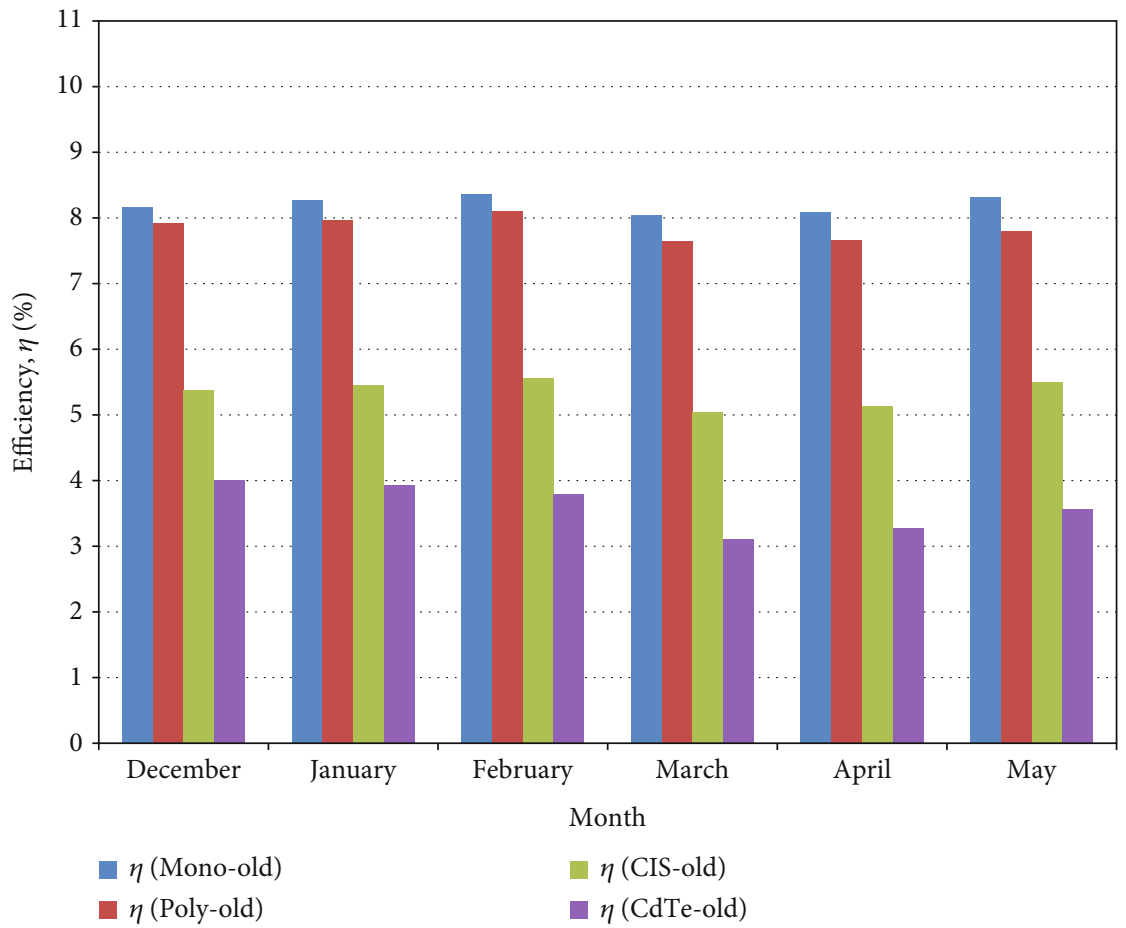

(b)

FIGURE 13: Monthly panel efficiency of (a) four new PV panels and (b) four 5-year-old PV panels.

show that a new monocrystalline PV panel (mono-new) has the highest efficiency values in all the months between December 2019 and May 2020, and new polycrystalline PV panel (Poly-new) has slightly less efficiency than mono-new in all the months. The maximum efficiency value of mono-new PV panel is estimated in February with 8.73\%, and the lowest efficiency value of this panel is estimated in March with $8.21 \%$.
Besides this, in December 2019, the monthly efficiency value of mono-new is $8.48 \%$ since the efficiency value of poly-new is $8.28 \%$ which is $0.20 \%$ lower than mono-new. The average 6-month efficiencies of new PV panels are $8.46 \%, 8.11 \%$, $5.65 \%$, and $3.88 \%$ for mono-new, poly-new, new CIS PV panel (CIS-new), and new CdTe PV panel (CdTe-new), respectively. According to the results, CIS-new is the third best PV panel, 
and the CdTe-new is the worst PV panel in terms of monthly panel efficiency estimation in all the months.

Figure 13(b) depicts monthly panel efficiency of 5-yearold PV panels between December 2019 and May 2020. According to the results, 5-year-old monocrystalline (mono-old) and 5-year-old polycrystalline (poly-old) PV panels have the best panel efficiencies in all the months as compared to the other old PV panel technologies. Besides this, 5-year-old CIS (CIS-old) and 5-year-old CdTe PV panels (CdTe-old) have the less panel efficiencies in all the months. Moreover, mono-old, poly-old, and CIS-old PV panels have the highest efficiencies in February whereas the CdTe-old PV panel has the maximum efficiency in December. March is the month that all 5-year-old PV panels have the lowest efficiencies. The average 6-month efficiencies of 5-year-old PV panels are 8.22\%, 7.85\%, 5.35\%, and 3.63\% for mono-old, poly-old, CIS-old, and CdTe-old, respectively. Among all 5-year-old PV panels, the mono-old PV panel has the best efficiency estimations in all the months. Furthermore, the average 6-month efficiency of mono-old PV panel is greater than the average 6-month efficiency of poly-new, CIS-new, and CdTe-new PV panels.

Consequently, the results in Figures 13(a) and 13(b) indicate that mono-new and mono-old PV panels are the best panel technologies among all the new and 5-year-old PV panels in terms of monthly panel efficiency, respectively. Even though mono-old PV panel has some degradation in time, it has better average 6-month efficiency than some of new PV panels.

Table 3 illustrates monthly average of humidity between December 2019 and May 2020 in Ankara. According to the results, the highest humidity is measured in December with $83.6 \%$, and the lowest humidity is measured in May with $55.1 \%$ in Ankara. Humidity affects electricity generating performance of PV panels. For instance, very small water drops on PV panels can reflect the sunlight away from PV panels, and this reduces producing power because less sunlight hits the surface of PV panels. According to Table 3, the least efficiencies of old and new PV panels are obtained in March when the humidity is high. On the other hand, the highest efficiencies of new and old PV panels are achieved in February when the humidity is low. Note that, even though humidity is an important factor which affects the performance of PV panels, there are other important factors that affect the performance of PV panels such as temperature, wind, and solar radiation.

\subsection{Statistical Analysis of Data}

3.7.1. Performance Analysis of PV Panels and Photovoltaic Panel Measurement System Using Nonparametric Tests. The purpose of using the nonparametric tests is to understand and analyze the performance, stability, and reliability of the PV panels. The main advantage of using the nonparametric tests is that they can handle probabilistic and nonprobabilistic measurements obtained from the PV panels without any limitation.

This section presents and examines different test results obtained using various nonparametric test measurement
TABLE 3: Monthly average of humidity between December 2019 and May 2020 in Ankara.

\begin{tabular}{lc}
\hline Month & Humidity in percentage (\%) \\
\hline December & $83.6 \%$ \\
January & $76.2 \%$ \\
February & $72.9 \%$ \\
March & $73.5 \%$ \\
April & $61.4 \%$ \\
May & $55.1 \%$ \\
\hline
\end{tabular}

TABLE 4: Average rankings of eight $\mathrm{PV}$ panels using the nonparametric statistical procedure, statistics, and $p$ values.

\begin{tabular}{lccc}
\hline PV panel type & Friedman & Friedman aligned & Quade \\
\hline CdTe-new & 4.314 & 19.203 & 4.262 \\
Mono-old & 4.399 & 22.996 & 4.768 \\
CIS-new & 3.242 & 8.408 & 3.036 \\
Poly-old & 5.592 & 13.205 & 5.855 \\
Poly-new & 2.492 & 5.546 & 2.079 \\
Mono-new & 1.714 & 3.206 & 1.121 \\
CdTe-old & 7.185 & 45.687 & 7.663 \\
CIS-old & 7.057 & 42.375 & 7.211 \\
\hline
\end{tabular}

approaches. In order to achieve the test results, three different nonparametric tests which are Friedman, Friedman Aligned, and Quade are applied to the efficiency values of eight PV panels as shown in Figures 13(a) and 13(b). The aim of applying Friedman, Friedman Aligned, and Quade nonparametric tests is to understand statistically whether there is any difference or similarity between the PV panels used over the given set of data. Note that these tests compute the ranks of the performance of the PV panels, i.e., the best performing PV panel receives the rank of 1, the second best rank 2, etc. The mathematical background and further details of the nonparametric methods can be obtained in [41-44]. In addition, more statistical experimental results based on Iman-Davenport, Bonferroni-Dunn, Holm, Hochberg, Holland, Rom, Finner, Li, Shaffer, and Bergamnn-Hommel tests as well as adjusted $p$ value has been computed using the publicly available JAVA software ${ }^{1}[41-44]$.

Table 4 shows the average ranking results estimated using the Friedman, the Friedman Aligned, and the Quade nonparametric tests. According to the results, mono-new PV panel is the best performing panel, with the average rank of 1.714, 3.206, and 1.121 for the Friedman, Friedman Aligned, and Quade tests, respectively. Moreover, the $p$ values have been calculated using the statistics of each of the tests applied (23.163, 5.148, and 15.613). Furthermore, the Iman Davenport statistic and $p$ value are computed $12.538 \times 10^{-7}$ , 0.4021 , and $7.128 \times 10^{-9}$, respectively. Furthermore, the poly-new performs very close to the mono-new with the second ranking place comparing to the others. The CdTeold gives the worst performance with the last ranking place 
TABLE 5: Adjusted $p$ values for Friedman (mono-new is the control PV panel).

\begin{tabular}{lcccccrr}
\hline PV panel & Unadjusted & Bonferroni & Holm/Hochberg/Hommel & Holland & Rom & Finner & Li \\
\hline CdTe-old & $6.143 \times 10^{-78}$ & $4.300 \times 10^{-77}$ & $4.300 \times 10^{-77}$ & 0.0 & $4.088 \times 10^{-77}$ & 0.0 & $6.191 \times 10^{-78}$ \\
CIS-old & $2.094 \times 10^{-74}$ & $1.466 \times 10^{-73}$ & $1.256 \times 10^{-73}$ & 0.0 & $1.194 \times 10^{-73}$ & 0.0 & $2.111 \times 10^{-74}$ \\
Poly-old & $4.643 \times 10^{-40}$ & $3.250 \times 10^{-39}$ & $2.321 \times 10^{-39}$ & 0.0 & $2.207 \times 10^{-39}$ & 0.0 & $4.680 \times 10^{-40}$ \\
Mono-old & $4.580 \times 10^{-20}$ & $3.206 \times 10^{-19}$ & $1.832 \times 10^{-19}$ & 0.0 & $1.747 \times 10^{-19}$ & 0.0 & $4.616 \times 10^{-20}$ \\
CdTe-new & $6.644 \times 10^{-19}$ & $4.651 \times 10^{-18}$ & $1.993 \times 10^{-18}$ & 0.0 & $1.993 \times 10^{-18}$ & 0.0 & $6.697 \times 10^{-19}$ \\
CIS-new & $1.778 \times 10^{-7}$ & $1.245 \times 10^{-6}$ & $3.557 \times 10^{-7}$ & $3.557 \times 10^{-7}$ & $3.557 \times 10^{-7}$ & $2.075 \times 10^{-7}$ & $1.793 \times 10^{-7}$ \\
Poly-new & 0.0078 & 0.0548 & 0.0078 & 0.0078 & 0.0078 & 0.0078 & 0.0078 \\
\hline
\end{tabular}

${ }^{1}$ http://sci2s.ugr.es/sicidm.

TABLE 6: Adjusted $p$ values for Friedman Aligned (mono-new is the control PV panel).

\begin{tabular}{lccccccc}
\hline PV panel & Unadjusted & Bonferroni & Holm/Hochberg/Hommel & Holland & Rom & Finner & Li \\
\hline CIS-old & $9.571 \times 10^{-47}$ & $6.699 \times 10^{-46}$ & $6.699 \times 10^{-46}$ & 0.0 & $6.369 \times 10^{-46}$ & 0.0 & $9.571 \times 10^{-47}$ \\
Poly-old & $1.039 \times 10^{-45}$ & $7.275 \times 10^{-45}$ & $6.236 \times 10^{-45}$ & 0.0 & $5.929 \times 10^{-45}$ & 0.0 & $1.039 \times 10^{-45}$ \\
CdTe-old & $1.634 \times 10^{-45}$ & $1.144 \times 10^{-44}$ & $8.172 \times 10^{-45}$ & 0.0 & $7.772 \times 10^{-45}$ & 0.0 & $1.634 \times 10^{-45}$ \\
CIS-new & $9.032 \times 10^{-45}$ & $6.322 \times 10^{-44}$ & $3.612 \times 10^{-44}$ & 0.0 & $3.407 \times 10^{-44}$ & 0.0 & $9.032 \times 10^{-45}$ \\
CdTe-new & $1.135 \times 10^{-44}$ & $7.951 \times 10^{-44}$ & $3.612 \times 10^{-44}$ & 0.0 & $3.407 \times 10^{-44}$ & 0.0 & $1.135 \times 10^{-44}$ \\
Mono-old & $2.970 \times 10^{-44}$ & $2.079 \times 10^{-43}$ & $5.940 \times 10^{-44}$ & 0.0 & $5.940 \times 10^{-44}$ & 0.0 & $2.970 \times 10^{-44}$ \\
Poly-new & $1.625 \times 10^{-35}$ & $1.137 \times 10^{-34}$ & $1.625 \times 10^{-35}$ & 0.0 & $1.625 \times 10^{-35}$ & 0.0 & $1.625 \times 10^{-35}$ \\
\hline
\end{tabular}

TABLE 7: Adjusted $p$ values for Quade (mono-new is the control PV panel).

\begin{tabular}{lccccccc}
\hline PV panel & Unadjusted & Bonferroni & Holm/Hochberg/Hommel & Holland & Rom & Finner \\
\hline CdTe-old & $3.656 \times 10^{-25}$ & $2.559 \times 10^{-24}$ & $2.559 \times 10^{-24}$ & 0.0 & $2.433 \times 10^{-24}$ & 0.0 & $4.198 \times 10^{-25}$ \\
CIS-old & $5.061 \times 10^{-22}$ & $3.542 \times 10^{-21}$ & $3.036 \times 10^{-21}$ & 0.0 & $2.887 \times 10^{-21}$ & 0.0 & $5.811 \times 10^{-22}$ \\
Poly-old & $6.416 \times 10^{-14}$ & $4.491 \times 10^{-13}$ & $3.208 \times 10^{-13}$ & $3.208 \times 10^{-13}$ & $3.051 \times 10^{-13}$ & $1.497 \times 10^{-13}$ & $7.367 \times 10^{-14}$ \\
Mono-old & $7.611 \times 10^{-9}$ & $5.328 \times 10^{-8}$ & $3.044 \times 10^{-8}$ & $3.044 \times 10^{-8}$ & $2.903 \times 10^{-8}$ & $1.332 \times 10^{-8}$ & $8.739 \times 10^{-9}$ \\
CdTe-new & $6.522 \times 10^{-7}$ & $4.565 \times 10^{-6}$ & $1.956 \times 10^{-6}$ & $1.956 \times 10^{-6}$ & $1.956 \times 10^{-6}$ & $9.130 \times 10^{-7}$ & $7.488 \times 10^{-7}$ \\
CIS-new & 0.0024 & 0.0162 & 0.0048 & 0.0048 & 0.0048 & 0.0028 & 0.0027 \\
Poly-new & 0.1290 & 0.9034 & 0.1290 & 0.1290 & 0.1290 & 0.1290 & 0.1290 \\
\hline
\end{tabular}

with the average rank of $7.185,45.687$, and 7.663 for the Friedman, Friedman Aligned, and Quade tests, respectively.

In the next statistical analysis, multiple comparison post hoc procedures (eight) are applied to evaluate the control of mono-new with the rest of $\mathrm{PV}$ panels. The results are illustrated by computing $p$ values for each comparison. Tables 5-7 depict the $p$ value results using the rankings computed by the Friedman, Friedman Aligned, and Quade tests, respectively [41-44]. These results verify the significant improvement of the usage of the mono-new PV panel over the other PV panels for all the post hoc procedures considered. Moreover, Li's statistical technique reaches the lowest $p$ values in the comparisons. Therefore, it is the most certain one among the others in order to reach the clearest conclusion.

Table 8 shows 10 different hypotheses using four different statistical techniques which are Nemenyi, Holm, Shaffer, and Bergmann to achieve $p$ values. According to the $p$ values, first four hypotheses by all the post hoc procedures are rejected because the levels of significance $(\alpha)$ is $\alpha=0.05$. For example, let us compare hypothesis 4 which is monoold vs. poly-old. The $p$ values estimated by Nemenyi, Holm, Shaffer, and Bergmann procedures [45 - 48] are less than $\alpha=0.05$ so we reject the hypothesis 4 for the mono-old vs. poly-old. The similar procedure is used for all the hypotheses so the first four hypotheses are rejected. On the other hand, other six hypotheses are not rejected because the computed $p$ values by Nemenyi, Holm, Shaffer, and Bergmann procedures are bigger than 0.05 . As a result, the hypotheses demonstrate the improvement of mono-new over CdTeold, CIS-old, and Poly-new and that of Poly-new panel over Poly-old. If $\alpha$ is 0.1 , then the first six hypotheses are rejected since the computed $p$ values of all the post hoc procedures for the first six hypotheses are less than 0.1 . However, the rest of hypothesis which are the hypotheses $7,8,9$, and 10 
TABLE 8: Adjusted $p$ values for tests for multiple comparisons among all PV panels.

\begin{tabular}{lccccc}
\hline Index & Hypothesis & Nemenyi [45] & Holm [46] & Shaffer [47] & Bergmann [48] \\
\hline 1 & Mono-new vs. CdTe-old & $4.981 \times 10^{-6}$ & $1.778 \times 10^{-6}$ & $1.778 \times 10^{-6}$ & $1.245 \times 10^{-6}$ \\
2 & Mono-new vs. CIS-old & $1.592 \times 10^{-5}$ & $5.120 \times 10^{-6}$ & $5.120 \times 10^{-6}$ & $6.293 \times 10^{-5}$ \\
3 & Poly-new vs. mono-new & $3.524 \times 10^{-4}$ & $1.007 \times 10^{-4}$ & $1.007 \times 10^{-4}$ & $1.845 \times 10^{-4}$ \\
4 & Poly-new vs. poly-old & 0.0012 & $3.229 \times 10^{-4}$ & $3.229 \times 10^{-4}$ & 0.0642 \\
5 & Mono-old vs. CIS-new & 0.0521 & 0.0634 & 0.0965 & 0.0586 \\
6 & CdTe-new vs. CIS-new & 0.0703 & 0.0862 & 0.3131 & 0.2342 \\
7 & Poly-new vs. mono-new & 0.2192 & 0.3131 & 0.3131 & 1.3210 \\
8 & CIS-new vs. poly-new & 0.2916 & 1.3210 & 1.3210 & 1.3210 \\
9 & CdTe-old vs. CIS-old & 18.495 & 1.3210 & & 1.3210 \\
\hline
\end{tabular}

TABLE 9: Global relevance of the research results.

\begin{tabular}{|c|c|c|c|c|}
\hline PV technology & Efficiency & Location & Evaluation period & Reference \\
\hline $\begin{array}{l}\text { Mono } \\
\text { Poly } \\
\text { CIGS } \\
\text { CdTe }\end{array}$ & $\begin{array}{c}11.20 \% \\
11.00 \% \\
9.20 \% \\
7.20 \%\end{array}$ & Nicosia/CYPRUS & Annual & [49] \\
\hline Poly & $8.30 \%$ & Katar-Kalan/India & Annual & {$[50]$} \\
\hline Mono & $5.40 \%$ & Brunei & 6 months & {$[51]$} \\
\hline $\begin{array}{l}\text { Mono } \\
\text { Poly }\end{array}$ & $\begin{array}{c}10.27 \% \\
9.56 \% \\
\end{array}$ & Agadir/Morocco & Annual & {$[52]$} \\
\hline Poly & $11.80 \%$ & Singapore & 18 months & {$[53]$} \\
\hline Poly & $7,60 \%$ & Calabria, Italy & 2 months & {$[54]$} \\
\hline $\begin{array}{l}\text { Poly } \\
\text { CIGS } \\
\text { CdTe }\end{array}$ & $\begin{array}{c}14.50 \% \\
11.00 \% \\
8.7 \%\end{array}$ & Poland & Annual & {$[55]$} \\
\hline $\begin{array}{l}\text { Mono } \\
\text { Poly } \\
\text { CIS } \\
\end{array}$ & $\begin{array}{l}11.20 \% \\
11.90 \% \\
10.80 \% \\
\end{array}$ & Hamirpur Himachal Pradesh/India & Annual & {$[56]$} \\
\hline $\begin{array}{l}\text { Mono } \\
\text { Poly } \\
\text { CIS } \\
\text { CdTe }\end{array}$ & $\begin{array}{l}8.46 \% \\
8.11 \% \\
5.65 \% \\
3.88 \%\end{array}$ & Ankara/Turkey & 6 months & Current study \\
\hline
\end{tabular}

are not rejected. By selecting $\alpha$ as 0.01 , we can evaluate more hypotheses. These hypotheses for $\alpha=0.01$ verify that mononew performs better than CdTe-old, CIS-old, and poly-new, and poly-new performs better than poly-old, and CIS-new performs better than mono-old and CdTe-new.

3.8. Global Relevance of the Research Results. Table 9 presents efficiency results of different PV panels in different cities and countries. For instance, in [49], performances of four different PV panels which are mono, poly, CIGS, and CdTe are analyzed in Nicosia, Cyprus, based on the data collected annually, and the results show that mono provides the best performance comparing to the other PV panels. Besides, the performance of mono PV panel has been analyzed in other countries such as Brunei, Morocco, India, and Turkey. However, the efficiency results have been obtained based on the different time durations. According to the results, it is clear that mono PV panel provides the best performance with $11.20 \%$ in Cyprus and India, and the efficiency of mono PV panel is the least with $5.40 \%$ in Brunei. Moreover, the highest and lowest efficiencies of poly are $14.50 \%$ and $7.60 \%$ in Poland and Italy, respectively. Note that, the efficiency results in Cyprus, India, and Poland are estimated based on the data which were collected annually. Therefore, efficiencies of mono and poly PV panels are higher than the efficiencies of mono and poly PV panels in Ankara. The main reason of getting lower efficiency of mono in Ankara is that the data was collected in winter and spring periods, and the efficiencies 
of mono and poly PV panels are with $8.46 \%$ and $8.11 \%$ for Ankara Province, Turkey, and it is important to emphasize that the efficiencies of the PV panels will be much higher when the summer data is taken into consideration. Furthermore, in other researches, only new PV panels were used for performance comparison. In our study, new and old PV panels have been used for performance assessment and analyses.

\section{Conclusions and Future Work}

This paper presents two different studies which are (1) a designed photovoltaic panel measurement and analysis system (PPMAS) and (2) a detailed performance analysis and comparison of four new and four 5-year-old PV panels which are based on polycrystalline, monocrystalline, CIS, and CdTe. The designed PPMAS system consists three different subsystems. In order to accurately obtain the atmospheric measurements and power generation of PV panels, the subsystems are calibrated. The designed PPMAS system with PV panels is installed in Yildirim Beyazit University Campus, Ankara, Turkey, and performed for six months between December 2019 and May 2020. According to the results, PPMAS system performs well to obtain measurements which are ambient temperature, wind speed, and panel temperature as well as the amount of power generation of PV panel. Besides this, eight PV panels, in which four of them are new and other four are 5-year-old PV panels, have been tested under the same weather conditions for 6 months. According to the results, February is the best month that mono, poly, and CIS have the best efficiency measurements whereas CdTe has the best measurement in December. Besides this, CdTe-based PV panel technology has the less efficiency measurements in all the months. Test results obtained from the experimental system are also statistically examined and discussed to analyze the performance of PV panels in terms of monthly panel efficiency.

The current version of the designed PPMAS can measure generated power of up to eight PV panels. As a future work, this system will be modified to measure generated power of more than eight PV panel technologies. Moreover, performance of different PV panel technologies in different locations of Turkey will be assessed and analyzed to understand efficiencies of PV panels in different locations in Turkey. In this work, we discussed the performance of PV panel technologies produced by monocrystalline, polycrystalline, CIS, and CdTe. Other PV panel technologies such as amorphous silicon (a-Si) and gallium arsenide- (GaAs-) based PV panels will also be used for performance assessment. The current PPMAS system can work three days under insufficient sun conditions with the help of its battery system. As a future work, the capacity of battery will be increased; thus, the system can work up to seven days under insufficient sun conditions.

\section{Data Availability}

The data used to support the findings of this study are available from the corresponding author upon request.

\section{Conflicts of Interest}

The authors declare that they have no conflicts of interest.

\section{Acknowledgments}

Huseyin Kusetogullari is funded by the research project "scalable resource efficient systems for big data analytics" by the Knowledge Foundation (Grant: 20140032) in Sweden. The experimental study was carried out in Yildirim Beyazit University Campus. The authors thank the Yildirim Beyazit University administration. Also, the authors would like to thank the management of Gazi Technopark and the relevant staff in Gazi University.

\section{References}

[1] IEA, Renewables 2019, IEA, Paris, 2019, March 2020 https://www.iea.org/reports/renewables-2019.

[2] C. J. Traverse, R. Pandey, M. C. Barr, and R. R. Lunt, "Emergence of highly transparent photovoltaics for distributed applications," Nature Energy, vol. 2, no. 11, pp. 849-860, 2017.

[3] G. G. Kim, J. H. Choi, S. Y. Park et al., "Prediction model for PV performance with correlation analysis of environmental variables," IEEE Journal of Photovoltaics, vol. 9, no. 3, pp. 832-841, 2019.

[4] S. W. Glunz, M. Bivour, C. Messmer et al., "Passivating and carrier-selective contacts-basic requirements and implementation," in 2017 IEEE 44th Photovoltaic Specialist Conference (PVSC), pp. 2064-2069, 2017.

[5] A. Bosio, S. Pasini, and N. Romeo, "The history of photovoltaics with emphasis on CdTe solar cells and modules," Coatings, vol. 10, no. 4, pp. 344-355, 2020.

[6] I. E. Tinedert, F. Pezzimenti, M. L. Megherbi, and A. Saadoune, "Design and simulation of a high efficiency CdS/CdTe solar cell," Optik, vol. 208, 2020.

[7] C. Y. Ou, S. Som, and C. H. Lu, "Incorporation of copperindium back-end layers in the solution-based $\mathrm{Cu}$ (In, Ga) Se2 films: enhancement of photovoltaic performance of fabricated solar cells," Materials Research Express, vol. 7, no. 2, pp. 5-18, 2020.

[8] A. G. Olabi, "Renewable energy and energy storage systems," Energy, vol. 136, pp. 1-6, 2017.

[9] M. F. Nayan, S. M. S. Ullah, and S. N. Saif, "Comparative analysis of PV module efficiency for different types of silicon materials considering the effects of environmental parameters," in 3rd International Conference on Electrical Engineering and Information Communication Technology (ICEEICT), pp. 1-6, Dhaka, 2016.

[10] A. Müller, M. Ghosh, R. Sonnenschein, and P. Woditsch, "Silicon for photovoltaic applications," Materials Science and Engineering: B, vol. 134, no. 2-3, pp. 257-262, 2006.

[11] C. E. C. Nogueira, J. Bedin, R. K. Niedzialkoski, S. N. M. de Souza, and J. C. M. das Neves, "Performance of monocrystalline and polycrystalline solar panels in a water pumping system in Brazil," Renewable and Sustainable Energy Reviews, vol. 51, pp. 1610-1616, 2015.

[12] M. Demirtaş, B. Tamyürek, E. Kurt, I. Çetinbaş, and M. K. Öztürk, "Effects of aging and environmental factors on performance of CdTe and CIS thin-film photovoltaic 
modules," Journal of Electronic Materials, vol. 48, no. 11, pp. 6890-6900, 2019.

[13] A. Taşçıŏlu, O. Taşkın, and A. Vardar, "A power case study for monocrystalline and polycrystalline solar panels in Bursa City, Turkey," International Journal of Photoenergy, vol. 2016, Article ID 7324138, 7 pages, 2016.

[14] E. Elibol, O. T. Özmen, N. Tutkun, and O. Köysal, "Outdoor performance analysis of different PV panel types," Renewable and Sustainable Energy Reviews, vol. 67, pp. 651-661, 2017.

[15] S. Seme, K. Sredenšek, B. Štumberger, and M. Hadžiselimović, "Analysis of the performance of photovoltaic systems in Slovenia," Solar Energy, vol. 180, pp. 550-558, 2019.

[16] M. S. Adaramola and E. E. Vågnes, "Preliminary assessment of a small-scale rooftop PV-grid tied in Norwegian climatic conditions," Energy Conversion and Management, vol. 90, pp. 458-465, 2015.

[17] L. M. Ayompe, A. Duffy, S. J. McCormack, and M. Conlon, "Measured performance of a $1.72 \mathrm{~kW}$ rooftop grid connected photovoltaic system in Ireland," Energy conversion and management, vol. 52, no. 2, pp. 816-825, 2011.

[18] M. Adar, Y. Najih, M. Gouskir, A. Chebak, M. Mabrouki, and A. Bennouna, "Three PV plants performance analysis using the principal component analysis method," Energy, vol. 207, p. $118315,2020$.

[19] L. Carmo de Lima, L. A. Ferreira, and H. B. L. Morais, "Performance analysis of a grid connected photovoltaic system in northeastern Brazil," Energy for Sustainable Development, vol. 37, pp. 79-85, 2017.

[20] Z. A. Eluma and A. S. Momodu, "Climate change mitigation and renewable energy for sustainable development in Nigeria: a discourse approach," Renewable and Sustainable Energy Reviews, vol. 76, pp. 72-80, 2017.

[21] A. Hamzeh, S. Hamed, Z. Al-Omari, A. Sandouk, and G. Aldahim, "First year performance of a PV plant in Jordan compared to PV plants in the region Int," Journal of Renewable Energy Research, vol. 5, pp. 983-990, 2015.

[22] H. Maammeur, A. Hamidat, L. Loukarfi, M. Missoum, K. Abdeladim, and T. Nacer, "Performance investigation of grid-connected PV systems for family farms: case study of north-west of Algeria," Renewable and Sustainable Energy Reviews, vol. 78, pp. 1208-1220, 2017.

[23] I. Marinić-Kragić, S. Nižetić, F. Grubišić-Čabo, and A. M. Papadopoulos, "Analysis of flow separation effect in the case of the free-standing photovoltaic panel exposed to various operating conditions," Journal of Cleaner Production, vol. 174, pp. 53-64, 2018.

[24] H. Rezk, I. Tyukhov, M. al-Dhaifallah, and A. Tikhonov, "Performance of data acquisition system for monitoring PV system parameters," Measurement, vol. 104, pp. 204-211, 2017.

[25] J. Machacek, Z. Prochazka, and J. Drapela, "System for measuring and collecting data from solar-cell systems," in 2007 9th International Conference on Electrical Power Quality and Utilisation, pp. 1-4, IEEE, 2007.

[26] A. El Hammoumi, S. Motahhir, A. Chalh, A. El Ghzizal, and A. Derouich, "Low-cost virtual instrumentation of PV panel characteristics using Excel and Arduino in comparison with traditional instrumentation," Renewables: Wind, Water, and Solar, vol. 5, no. 1, 2018.

[27] M. A. Muñoz-García, O. Marin, M. C. Alonso-García, and F. Chenlo, "Characterization of thin film PV modules under standard test conditions: results of indoor and outdoor measurements and the effects of sunlight exposure," Solar Energy, vol. 86, no. 10, pp. 3049-3056, 2012.

[28] S. Kivrak and T. Özer, "Solar panels characteristic determining circuit design and implementation," International Journal of Latest Technology in Engineering, Management \& Applied Science, vol. 7, no. 11, pp. 1-4, 2018.

[29] D. Polverini, M. Field, E. Dunlop, and W. Zaaiman, "Polycrystalline silicon PV modules performance and degradation over 20 years," Progress in Photovoltaics: Research and Applications, vol. 21, no. 5, pp. 1004-1015, 2013.

[30] A. M. Ghazali and A. M. A. Rahman, "The performance of three different solar panels for solar electricity applying solar tracking device under the Malaysian climate condition," Energy and Environment Research, vol. 2, no. 1, 2012.

[31] M. Kumar and A. Kumar, "Performance assessment and degradation analysis of solar photovoltaic technologies: a review," Renewable and Sustainable Energy Reviews, vol. 78, pp. 554-587, 2017.

[32] T. Khatib, W. Elmenreich, and A. Mohamed, "Simplified I-V characteristic tester for photovoltaic modules using a dc-dc boost converter," Sustainability, vol. 9, no. 4, pp. 657-665, 2017.

[33] E. Durán, J. Galán, J. M. Andújar, and M. Sidrach-de-Cardona, "A new method to obtain IV characteristics curves of photovoltaic modules based on SEPIC and cuk converters," EPE Journal, vol. 18, pp. 5-15, 2015.

[34] S. Sarikh, M. Raouf, A. Bennouna, A. Benlarabi, and B. Ikken, "Design of an IV characteristic tracer for photovoltaic systems," in 2017 International Renewable and Sustainable Energy Conference (IRSEC), pp. 1-5, 2017.

[35] Y. Du, C. J. Fell, B. Duck et al., "Evaluation of photovoltaic panel temperature in realistic scenarios," Energy Conversion and Management, vol. 108, pp. 60-67, 2016.

[36] K. A. Moharram, M. S. Abd-Elhady, H. A. Kandil, and H. El-Sherif, "Enhancing the performance of photovoltaic panels by water cooling," Ain Shams Engineering Journal, vol. 4, no. 4, pp. 869-877, 2013.

[37] M. Z. Jacobson and V. Jadhav, "World estimates of PV optimal tilt angles and ratios of sunlight incident upon tilted and tracked PV panels relative to horizontal panels," Solar Energy, vol. 169, pp. 55-66, 2018.

[38] P. Michael, A Conversion Guide: Solar Irradiance and Lux Illuminance, IEEE Dataport, 2019.

[39] Tarim ve Orman Bakanligi Meteoroloji Genel Müdürlügü, Resmi İstatistiklerAugust 2020 Available: https://www.mgm .gov.tr/veridegerlendirme/il-ve-ilceler-istatistik.aspx.

[40] A. Çağlar, C. Yamalı, D. K. Baker, and B. Kaftanoğlu, "Measurement of solar radiation in Ankara, Turkey," Journal of Thermal Science and Technology, vol. 33, no. 2, pp. 135-142, 2013.

[41] D. J. Sheskin, Handbook of Parametric and Nonparametric Statistical Procedures, Chapman \& Hall/CRC, 4th edition, 2006.

[42] W. H. Kruskal and W. A. Wallis, "Use of ranks in one-criterion variance analysis," Journal of the American Statistical Association, vol. 47, no. 260, pp. 583-621, 1952.

[43] D. Quade, "Using weighted rankings in the analysis of complete blocks with additive block effects," Journal of the American Statistical Association, vol. 74, no. 367, pp. 680-683, 1979.

[44] W. Daniel, Applied nonparametric statistics, Duxbury Thomson Learning, 2nd edition, 2000. 
[45] P. B. Nemenyi, Distribution-free multiple comparisons Princeton University, master's thesis, 1963.

[46] S. Holm, "A simple sequentially rejective multiple test procedure," Scandinavian Journal of Statistics, vol. 6, no. 2, pp. 65-70, 1979.

[47] J. P. Shaffer, "Modified sequentially rejective multiple test procedures," Journal of the American Statistical Association, vol. 81, no. 395, pp. 826-831, 1986.

[48] B. Bergmann and G. Hommel, "Improvements of general multiple test procedures for redundant systems of hypotheses," in Multiple Hypothesenprüfung/Multiple Hypotheses Testing, pp. 100-115, Springer, Berlin, Heidelberg, 1988.

[49] G. Makrides, B. Zinsser, G. E. Georghiou, M. Schubert, and J. H. Werner, "Outdoor efficiency of different photovoltaic systems installed in Cyprus and Germany," in 2008 33rd IEEE Photovoltaic Specialists Conference, pp. 1-6, 2008.

[50] V. Sharma and S. S. Chandel, "Performance analysis of a 190 kWp grid interactive solar photovoltaic power plant in India," Energy, vol. 55, pp. 476-485, 2013.

[51] A. Q. Malik and S. J. B. H. Damit, "Outdoor testing of single crystal silicon solar cells," Renewable Energy, vol. 28, no. 9, pp. 1433-1445, 2003.

[52] A. Tihane, M. Boulaid, A. Elfanaoui, M. Nya, and A. Ihlal, "Performance analysis of mono and poly-crystalline silicon photovoltaic modules under Agadir climatic conditions in Morocco," Materials Today: Proceedings, vol. 24, pp. 85-90, 2020.

[53] S. Wittkopf, S. Valliappan, L. Liu, K. S. Ang, and S. C. J. Cheng, "Analytical performance monitoring of a $142.5 \mathrm{kWp}$ gridconnected rooftop BIPV system in Singapore," Renewable Energy, vol. 47, pp. 9-20, 2012.

[54] M. Cucumo, A. De Rosa, V. Ferraro, D. Kaliakatsos, and V. Marinelli, "Performance analysis of a $3 \mathrm{~kW}$ grid-connected photovoltaic plant," Renewable Energy, vol. 31, no. 8, pp. 1129-1138, 2006.

[55] S. Gulkowski, A. Zdyb, and P. Dragan, "Experimental efficiency analysis of a photovoltaic system with different module technologies under temperate climate conditions," Applied Sciences, vol. 9, no. 1, pp. 141-151, 2019.

[56] N. Kumar, P. Yadav, and S. S. Chandel, "Comparative analysis of four different solar photovoltaic technologies," in 2015 International Conference on Energy Economics and Environment (ICEEE), pp. 1-6, 2015. 